\title{
Therapeutic Advances in Interventional Neurology
}

\author{
Jawad F. Kirmani, Nazli Janjua, Ammar Al Kawi, Shafiuddin Ahmed, Ismail Khatri, \\ Ali Ebrahimi, Afshin A. Divani, and Adnan I. Qureshi \\ Zeenat Qureshi Stroke Research Center, Department of Neurology and Neurosciences, \\ University of Medicine and Dentistry of New Jersey, Newark, New Jersey 07103
}

\begin{abstract}
Summary: Rapid advances in the field of interventional neurology and the development of minimally invasive techniques have resulted in a great expansion of potential therapeutic applications. We discuss therapeutic interventional neurology as applied in clinical practice in one of the two possible ways: 1) embolization leading to occlusion of blood vessels; and 2) revascularization leading to reopening of blood vessels. These procedures can be applied to a broad range of cerebrovascular
\end{abstract}

diseases. In the first section of this review, we will explore the evolution of these interventions to occlude aneurysms, arteriovenous malformations, neurovascular tumors, and injuries. In the second section, revascularization in acute ischemic stroke, stenosis, and dural venous thrombosis will be discussed. Key Words: Interventional neuroimaging, ischemic stroke, intracranial aneurysm, cerebral vasospasm, arteriovenous malformation, cerebral venous thrombosis, embolization.

\section{SECTION I: EMBOLIZATION}

\section{Intracranial aneurysms}

Subarachnoid hemorrhage (SAH) is a common and often devastating occurrence. Each year approximately 30,000 Americans experience a nontraumatic aneurysmal subarachnoid hemorrhage. ${ }^{1,2}$ Intracranial aneurysms constitute an important health problem worldwide, affecting about $2 \%$ of the population. ${ }^{3}$

The first reported endovascular attempt at approaching an aneurysm was reported in 1941, when Werner and colleagues inserted silver wires via transorbital approach to prevent rupture of a susceptible wall of an aneurysm from the stress of pulsatile blood. ${ }^{4}$ Subsequently, placement of particles and other agents including platinum coils was attempted. ${ }^{5}$ By the late 1980 s, platinum coils had been introduced. These were attached to a steel delivery wire system that could be delivered through a microcatheter to aneurysmal sac. ${ }^{6}$ Subsequently, an electrical current applied to the wire attached to the coil was used to detach the stainless steel wire from the platinum coil. The protection provided by the coil inside the aneurysm was thought to be due to immediate hemodynamic changes and redirection of the blood flow through

Address correspondence and reprint requests to Jawad F. Kirmani, M.D., 90 Bergen Street, Doctor's Office Center 8100, Newark, NJ 07103. E-mail: jkirmani@ hotmail.com. the proper vessel. An eventual thrombus formed within the aneurysm that protects the osteal neck of the aneurysm and eventually fills the inner cavity with connective tissue. $^{7}$

Endovascular treatment is usually performed under general anesthesia. In a very selective group of patients, it may be done in the awake state. ${ }^{8}$ The endovascular coils are placed in the aneurysmal sac either with the assistance of a balloon, stent, another microcatheter or with support of the original microcatheter itself. Better coil designs have improved the ability to obliterate the aneurysmal sacs. A liquid embolic agent such as ethyl vinyl alcohol polymer may also be used in conjunction with intravascular stents to obliterate complex aneurysms. ${ }^{9}$

Initially, endovascular treatment was reserved for patients who were regarded as poor candidates for surgical clipping. It included patients who were elderly ${ }^{10}$; those with poor Hunt-Hess grades IV or $\mathrm{V}^{11}$; those whose aneurysms are located in the posterior circulation ${ }^{12}$ or were located in cavernous segment of internal carotid artery ${ }^{13}$; and had active cerebrovasospasm. ${ }^{14}$

With the improvement in clinical experience and coil design, embolization has been attempted for patients referred for treatment with conventional surgical clipping in the past. ${ }^{15}$ Investigators from Finland compared endovascular treatment of ruptured aneurysms with surgical clipping confirming the effectiveness and safety pro- 
file of coil embolization. ${ }^{16}$ The mortality-related technique of coiling was comparable to the surgical group. There was no difference in short-term clinical outcome between the two major treatment methods. Angiographic outcome in the anterior circulation was better in the surgical group, whereas endovascular treatment fared better in the posterior circulation. This was a phase II trial with 57 patients in the surgical clipping arm and 52 patients in embolization arm. Patients were recruited within $72 \mathrm{~h}$ of aneurysmal subarachnoid hemorrhage. The technique-related mortality rate was $4 \%$ in the surgical group and $2 \%$ in the endovascular group. ${ }^{16}$

A recently concluded, larger randomized multicenter phase III trial (International Subarachnoid Aneurysm Trial [ISAT]), ${ }^{17}$ compared the safety and efficacy of embolization with neurosurgical clipping. ISAT enrolled 2143 patients with ruptured aneurysms who were considered suitable for either treatment. The neurosurgical clipping group had 1070 patients and the group receiving endovascular treatment by detachable platinum coils had 1073 patients. The clinical outcomes were assessed at 2 months and at 1 year with interim ascertainment of rebleeds and death. Of the 801 patients allocated to endovascular treatment, $190(23.7 \%)$ became dependent or died at 1 year compared with 243 (30.6\%) of 793 allocated to neurosurgical treatment $(p=0.0019)$. The risk of rebleeding from ruptured aneurysms after 1 year was two per 1276 and zero per 1081 patients allocated to endovascular and neurosurgical treatment, respectively. It was concluded that the outcomes in terms of survival free of disability at one year was significantly better with endovascular coiling. ${ }^{17}$ Long-term follow-up in the patients enrolled in ISAT study will hopefully add more information about long-term durability of coiling in patients with ruptured aneurysms. A similar direct comparison between endovascular and surgical treatment for unruptured aneurysms is not available.

Hospital outcomes with unruptured intracranial aneurysms have improved since the introduction of detachable coils. A retrospective analysis of outcomes of surgery versus embolization of unruptured aneurysms using data from 60 university medical centers was published by Johnston et al. in $1999 .{ }^{18}$ Factors such as age, sex, race, mode of admission to the hospital, and year of treatment were taken into account. Endovascular coil embolization resulted in fewer adverse outcomes in surgery or unruptured cerebral aneurysms. Rates of in-hospital mortality, adverse outcomes defined by subsequent discharge to rehabilitation institution or nursing homes, length of stay, and cause of treatment were all substantially greater for surgical patients compared with endovascular coiling. Several studies examining uncontrolled series of patients have been published demonstrating the safety and effectiveness of embolization of cerebral aneurysms.
Considerable advances have been made in the ability to use coils for endovascular treatment of intracranial aneurysms in situations that might have appeared unsuitable a few years ago. The new designs of coils, including the three- and two-dimensional configurations, have improved results. Focusing on the anatomy of the aneurysm and on the neck and dome ratio, as well as its packing with coils in a step-wise manner, has led to remarkable success in coiling of aneurysms previously considered to be difficult.

Development of techniques, particularly temporary balloons and permanently placed stents, especially designed for intracranial vessels such as the Neuroform stent (SMART Therapeutics, Inc., San Leandro, CA), have helped with reconstruction techniques for coiled stabilization within intracranial aneurysms. ${ }^{19}$ The future of interventional techniques for aneurysm embolization is exciting, with higher standards for devices and availability of therapeutic options, substantiated with results from future randomized trials. Figure 1 illustrates an example of coiling in a relatively large symptomatic carotid aneurysm.

\section{Arteriovenous malformations}

CNS arteriovenous malformations (AVMs) occur in approximately $0.15 \%$ of the United States population. Of these, $90 \%$ are supratentorial in location. ${ }^{20,21}$ There is a rate of approximately $4 \%$ hemorrhagic conversion per year for cerebral AVMs. They carry a combined morbidity and mortality rate of $2.7 \%$ per year. ${ }^{21}$ AVMs can cause headaches, seizures, and ischemia. The treatment of AVMs is challenging and multifaceted. They pose a unique problem and often require a combination of therapeutic modalities. ${ }^{20}$ Embolization of cerebral AVMs on its own is curative in fewer than one-quarter of lesions. ${ }^{22,23}$

Embolization has been used for the following purpose: 1) adjunct to surgery; 2) reduction of size before radiation; 3) palliation; and 4) embolization alone for cure. To understand the role of endovascular treatment in AVM management, a brief overview of other modalities is presented.

The efficacy of microvascular AVM resection for preventing hemorrhage and reducing seizures in patients who present with epilepsy has been ${ }^{24}$ and is widely practiced. Although the feasibility of surgical resection has been significantly advanced, it is also clear that certain AVMs are associated with unacceptably high surgical risks. The Spetzler-Martin scale attempts to quantify this differential risk by analyzing three AVM factors including size, venous drainage, and eloquence of the involved cortex (Table 1). A larger AVM with deep venous drainage and eloquent cortex has been associated with poor surgical outcomes. 


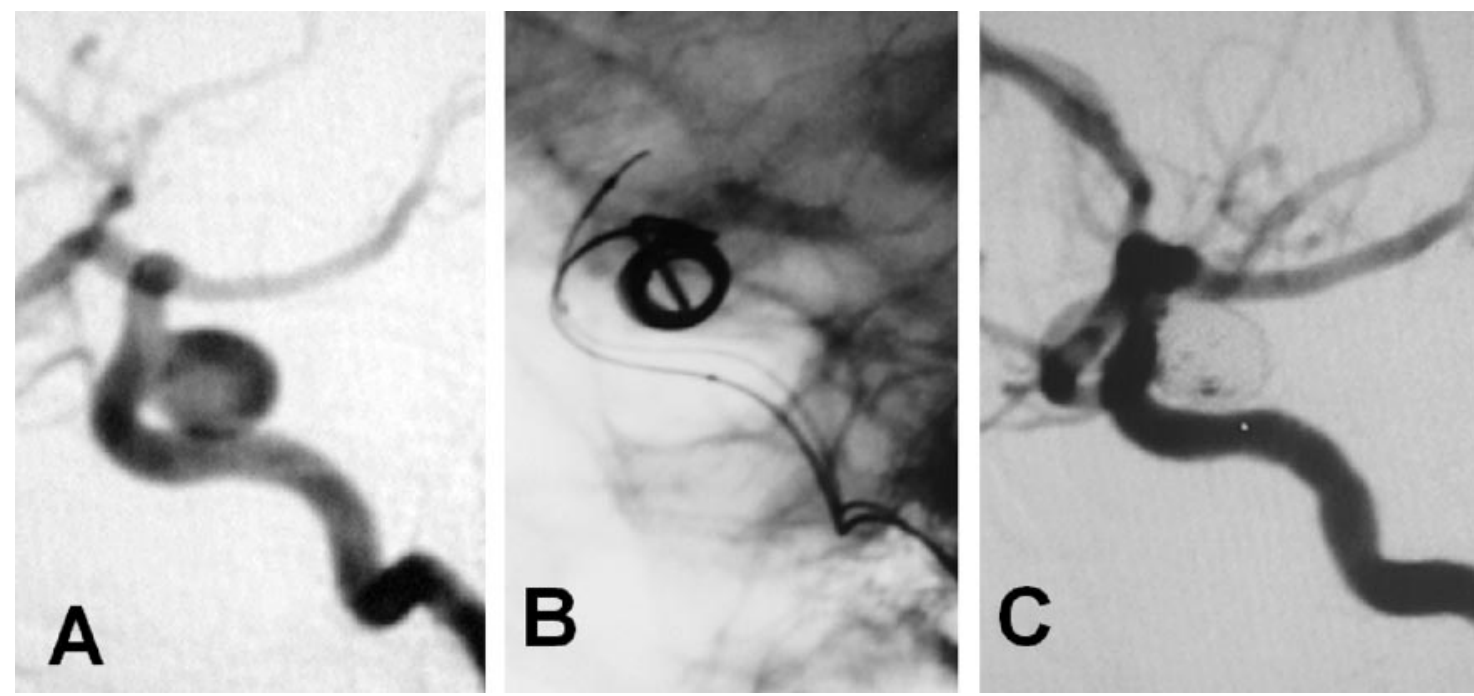

FIG. 1. A: Case illustration of a symptomatic $8.5 \times 8 \mathrm{~mm}$ ruptured intracranial carotid aneurysm. B: GDCs being deployed. C: Final result with minimal residual flow in the aneurysm but excellent patency of the parent vessel.

Embolization is performed using a microcatheter placed in a distal arterial feeder that supplies the AVM nidus exclusively. The nidus of the AVM is the focus of the embolization procedure. Any abnormal branches are excluded on the basis of assessment of vessel architecture and at times physiological testing by injection of short-acting amobarbital sodium and lidocaine through a microcatheter ${ }^{25}$ (technique is explained in detail in Section II). There are different embolic materials available. Solid embolic agents consist of polyvinyl alcohol particles, fibers, micro-coils, and micro-balloons. Liquid em-

TABLE 1. Spetzler Martin Grading Scale and Incidence of Postoperative Deficit in Relation to the Spetzler Martin Grading Scale

\begin{tabular}{|c|c|c|}
\hline \multicolumn{2}{|c|}{ Grade Feature } & Points \\
\hline \multicolumn{3}{|l|}{ Size } \\
\hline \multicolumn{2}{|c|}{ Small $<3 \mathrm{~cm}$} & 1 \\
\hline \multicolumn{2}{|c|}{ Medium 3-6 cm } & 2 \\
\hline \multicolumn{2}{|c|}{ Large $>6 \mathrm{~cm}$} & 3 \\
\hline \multicolumn{3}{|c|}{ Eloquence of adjacent brain } \\
\hline \multicolumn{2}{|c|}{ Noneloquent } & 0 \\
\hline \multirow{2}{*}{\multicolumn{3}{|c|}{$\begin{array}{l}\text { Eloquent } \\
\text { Pattern of venous drainage }\end{array}$}} \\
\hline & & \\
\hline \multicolumn{3}{|c|}{ Superficial } \\
\hline \multicolumn{2}{|c|}{ Deep } & 1 \\
\hline Grade & Minor Deficit $\%$ & Major Deficit $\%$ \\
\hline I & 0 & 0 \\
\hline II & 5 & 0 \\
\hline III & 12 & 4 \\
\hline IV & 20 & 7 \\
\hline V & 19 & 12 \\
\hline
\end{tabular}

Adding points on the scale constitutes a total Grade. bolic agents consist of cyanoacrylate monomers and polymer solutions such as ethyl vinyl alcohol polymer.

The usual goal of presurgical embolization is to decrease the nidus size and prevent perioperative blood loss associated with AVM resection. Hence, this enhances the safety and ease of operative neurological intervention. Embolized AVM vessels can also serve as a road map during surgical intervention. Because AVM embolization carries a certain amount of risk, AVMs that would significantly benefit from embolization before surgery should undergo this treatment. For example, a small AVM in the right frontal lobe with easily accessible arterial feeders may not warrant embolization before surgery. Also, radiosurgery has emerged as a relatively safe way to treat small AVMs. ${ }^{26}$ Two indirect comparisons have suggested that embolization before surgery can shorten operative time reducing intraoperative blood loss and can improve neurological outcomes in patients with complex AVMs such that they are comparable to those with less complex lesions. ${ }^{27}$ In a randomized trial comparing N-butyl-2-cyanoacrylate (NBCA) and polyvinyl alcohol for presurgical embolization of AVMs, embolization was not possible for technical reasons in three of 52 randomized patients, and there were two crossovers. The final lesion reduction after embolization was approximately $79 \%$ for patients given NBCA, and $87 \%$ for those given polyvinyl alcohol. The rate of good neurological recovery after embolization was $96 \%$ and $93 \%$, respectively, for NBCA and polyvinyl alcohol group. There were no significant differences in intraoperative time and blood loss. ${ }^{28}$ The usual goal of embolization is to reduce the nidus of the AVM to less than $3 \mathrm{~cm}$ and obliterate intranidal or venous aneurysm before radiosurgery or open surgical intervention. ${ }^{29}$ In the same study, 

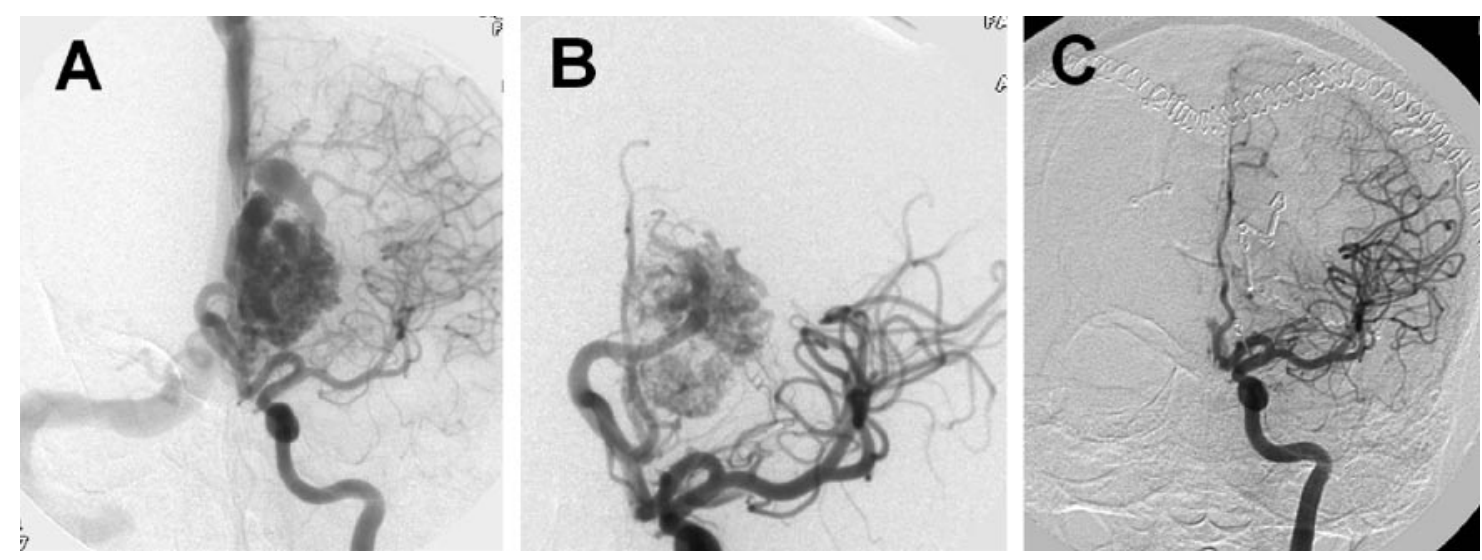

FIG. 2. A case illustration of an AVM. A: AVM before intervention. B: AVM after staged embolization. C: AVM after surgery. A staged embolization was performed. A large amount of shunting is seen with decreased transit times and early venous filling in panel $A$. Predominant flow toward the anterior cerebral artery in panel A was converted into a smaller AVM after staged embolizations in pane $\mathrm{B}$. Also, note that there is robust filling of the middle cerebral artery and no diversion in the venous sinuses in B. The postsurgical results are excellent with almost no flow into the nidus of the AVM (C).

angiographic follow-up of the AVMs, embolized with cyanoacrylate, demonstrated a $12 \%$ recanalization rate within 1 year. ${ }^{29}$ Dural arteriovenous fistulas derive from meningeal arteries and drain into dural sinuses or meningeal veins and can have retrograde drainage into subarachnoid veins. ${ }^{30}$ Treatment options include a combination of transarterial and transvenous or separate endovascular intervention. In patients with fistulas related to venous hypertension, recanalization with angioplasty or stents may be effective. ${ }^{31}$ Palliative embolization is reserved for patients with large, inoperable cortical and subcortical AVMs presenting with seizures refractory to medical management with progressive neurological deficits thought to be secondary to venous hypertension and/or arterial steal. ${ }^{32}$ The general consensus for endovascular treatment is to use Spetzler-Martin grade 2 or 3 lesions for presurgical or radiosurgical embolization. Grade 4 or 5 lesions are generally not embolized unless this is in conjunction with other treatment modalities such as surgery or radiosurgery for the goal of complete cure. The exception to this rule may be a grade 4 or 5 lesion with a venous outflow obstruction. ${ }^{32}$ Figure 2 shows an example of an AVM associated with intractable seizures.

\section{Traumatic neurovascular injury}

Transcatheter occlusion of traumatically injured vessels to control life-threatening bleeding represents some of the earliest endovascular procedures. ${ }^{33,34}$ Penetrating injury to the arteries of the head and neck may lead to dissection and pseudoaneurysm formation with the dreaded consequence of high-pressure arterial hemorrhage. Endovascular stenting of dissected intimal flaps aids in tacking down the affected vessel wall and preventing downstream dissection. This has been well described for injuries to the carotid, vertebral, and subclavian arteries. ${ }^{35,36}$
Aside from endovascular stenting, coil embolization of traumatically induced bleeding fistulas and pseudoaneurysms of the head and neck may also be performed to achieve vessel hemostasis. This is performed using liquid embolic agents such as coils (Bernstein liquid coils), particles (polyvinyl alcohol), or glue (NBCA) ${ }^{37}$ Detachable balloons as well as Guglielmi detachable coils may also be used. ${ }^{37-39}$

The approach to brachiocervical vessels involves a routine transfemoral arterial approach to the subclavian, carotid, or vertebral arteries. However, if trauma involves the skull, with resultant intracranial vascular injury, endovascular navigation becomes more complicated. Head and facial injuries may result in petrous or cavernous carotid dissection and fistula formation, and may require a transvenous approach to the arterial side. ${ }^{40}$

\section{Head and neck tumors}

Previously restricted to treatment by oncologists and surgeons, tumors of the head and neck are now also being treated by those skilled in endovascular neurological techniques. Recent endovascular intervention has involved clinical trials aimed at delivering chemotherapeutic agents directly to the tumor region, with the hypothesis that intra-arterial (IA) delivery would increase the concentration of the medication at the tumor site while minimizing side effects of systemic administration. Many of these trials showed no benefit for intra-arterial chemotherapy instillation, but trials are ongoing..$^{41,42}$ More importantly endovascular neurointervention offers a means for preoperative embolization of highly vascular tumors, thus reducing the complexity and complications of blood loss during surgery. In addition to neurovascular tumors that may benefit from embolization, hemangiomas, vascular malformations, and lymphovenous malformations of the head and neck may also benefit from endovascular therapy. 
The earliest experience of endovascular treatment of head and neck tumors dates to 1904 when Dawbarn performed transcarotid paraffin and petroleum embolization of a facial sarcoma. ${ }^{43}$ In 1972 Heckster et al. ${ }^{44,45}$ reported that preoperative tumor embolization aided surgical resection, findings that were reiterated in 1976 by Pandya and Nagpal in India. ${ }^{45,46}$ In 2001, guidelines regarding head, neck, and brain tumor embolization were published as part of a policy statement written for the Accreditation Council of Graduate Medical Education. They set eight criteria as indications for CNS tumor embolization: 1) achieving control of surgically inaccessible arterial feeders; 2 ) decreasing surgical morbidity by reducing operative blood loss; 3 ) shortening operative procedural time; 4) improving the likelihood of complete surgical resection; 5) decreasing the risk of damage to the adjacent normal tissue; 6) relieving intractable pain; 7) decreasing tumor recurrence; and 8) allowing better visualization of the surgical field, thereby reducing surgical complications. ${ }^{47}$

With the exception of the goal of reducing pain, endovascular intervention is largely adjuvant therapy to more definitive surgical management. Yet some patients are poor candidates for surgical treatment because of medical comorbidities, advanced cancer, or surgically inaccessible or inoperable lesions such as brainstem tumors. In these patients, endovascular therapy offers palliation of tumor burden and its associated consequences. With recent advances in endovascular techniques, there have been sporadic reports that such therapy may even be curative for intracranial tumors. ${ }^{48}$ In addition, endovascular tumor embolization must sometimes be undertaken on an emergent basis to control intractable, lifethreatening tumor hemorrhage. This is particularly important for oropharyngeal and laryngeal tumors, treated primarily by otolaryngologists, similar to intractable epistaxis, also treated endovascularly.

Hypervascular neurovascular tumors suitable for endovascular treatment include hemangioblastomas, meningiomas, hemangiopericytomas, schwannomas and other neurogenic tumors, paragangliomas, juvenile nasopharyngeal angiofibromas, hemangiomas, esthesioneuroblastomas, bone tumors, and intra- and extracranial metastatic tumors. ${ }^{47}$ Of these, meningiomas, which constitute $13-18 \%$ of all primary intracranial tumors, ${ }^{45}$ likely represent the most common tumor for which preoperative embolization is considered standard practice. In 1978, Brismar and Conqvist reported the use of Gelfoam (Upjohn, Kalamazoo, MI) to embolize meningiomas among four patients. ${ }^{45,49}$ Two larger series of patients who underwent preoperative meningioma embolization have since been published. Both advocated an interim of 5-7 days between embolization and surgery. ${ }^{45,50,51}$

In routine practice, meningioma, and other tumor em- bolization, when performed on an elective basis, is often planned 1-2 days before surgery. Tumor necrosis begins within $24 \mathrm{~h}$ after embolization and may peak at 4 days, as seen by magnetic resonance spectroscopy (MRS). ${ }^{52}$ Whether this is advantageous or deleterious during subsequent surgery has not been studied in clinical trials. The large series of Menalfe et al. also identified meningioma features particularly amenable to endovascular therapy including pure or predominant external carotid artery (ECA) blood supply (e.g., convexity, skull base, middle fossa or paracavernous meningiomas) and parasagittal tumors supplied by the contralateral middle meningeal artery. ${ }^{45,51}$

More recent series have included small clinical trials comparing patients undergoing surgery for meningioma resection who underwent preoperative embolization with those who did not. Reduction of intraoperative bleeding was demonstrated among patients who received endovascular treatment. ${ }^{45,53}$ Of note, embolization was performed $24-48 \mathrm{~h}$ before surgery in these patients.

Methods of embolization involve a standard angiographic transfemoral approach to the cranial vasculature. Though embolization is usually restricted to the external carotid artery (ECA) system, the internal carotid artery (ICA) is often studied to assess important orbital anastomoses between the ECA and ICA. Superselective catheterization using microcatheters is then undertaken to localize the territory targeted for treatment. Embolization is then performed using $150-250 \mu \mathrm{m}$ polyvinyl alcohol particles, Gelfoam powder or strips, or ethanol. ${ }^{42,45}$ Follow-up angiography of the ECA and ICA is then performed to assess the reduction in tumor blush and assess for interruption in orbital blood supply. Direct injection of absolute alcohol (dehydrated alcohol, 98\% ethylalcohol), or sodium tetradecyl sulfate for the treatment of superficially accessible lesions such as hemangiomas, vascular malformations, and lymphovenous malformations of the head and neck may be performed.

Early studies of intracarotid injection of carmustine did not show greatly improved outcomes among endovascularly-treated patients in treating glial malignancies. ${ }^{41,42}$ Increased rates of side-effects including leukoencephalopathy and visual loss were reported among the group receiving IA therapy. Modification of delivery, involving multiple target vessels, has improved tolerance to IA carmustine administration in subsequent studies. Ongoing trials for IA lobradimil, a bradykinin analog, and carboplatin are in their second phase of safety analysis. ${ }^{42,54,55}$

\section{SECTION II: REVASCULARIZATION}

\section{Acute ischemic stroke}

There has been improvement in outcome of stroke after the advent of intravenous (IV) recombinant tissue 
TABLE 2. Qureshi Grading Scheme for Stratification of Patients with Acute Ischemic Stroke Based on Initial Site of Occlusion and Collateral Supply

\begin{tabular}{|c|c|c|c|}
\hline Grade & \multicolumn{3}{|c|}{ Comment } \\
\hline 0 & & No occlusi & \\
\hline 1 & $\begin{array}{l}\text { MCA occlusion } \\
\text { (M3 segment) }\end{array}$ & ACA occlusion (A2 or distal segments) & One BA/VA branch occlusion \\
\hline 2 & $\begin{array}{r}\text { MCA occlusion } \\
\text { (M2 segment) }\end{array}$ & ACA occlusion (A1 and A2 segments) & Two or more BA/VA branch occlusions \\
\hline 3 & & MCA occlusion (M & 1 segment) \\
\hline $3 \mathrm{~A}$ & & Lenticulostriate arteries spared and/or le & ptomeningeal collaterals visualized \\
\hline 3B & & No sparing of lenticulostriate arteries no & r leptomeningeal collaterals visualized \\
\hline 4 & & ICA occlusion (collaterals present) & BA occlusion (partial filling directly or via collaterals) \\
\hline $4 \mathrm{~A}$ & & Collaterals fill the MCA & predominant Anterograde filling \\
\hline 4B & & Collaterals fill the ACA & predominant Retrograde filling \\
\hline 5 & & ICA occlusion (no collaterals) & BA occlusion (no collaterals) \\
\hline
\end{tabular}

ACA-anterior cerebral artery; BA-basilar artery; VA-vertebral artery. The interobserver variability and correlation with recanalization and short-term favorable outcome and mortality have been described in patients with acute ischemic stroke undergoing intra-arterial thrombolysis previously.

plasminogen activator (rtPA) for the treatment of acute ischemic stroke. Conversely, there are still many patients (57-58\%) who die or become dependent despite receiving IV rtPA. ${ }^{42,56-58}$ This has prompted the search for better drugs and better ways of delivery to the site of interest to achieve higher rates of recanalization within a shorter time frame with minimal risk to the patient. In 2002, a new grading system was proposed by Qureshi for assessing pretreatment of vascular occlusion that correlates better with 7-day outcome when compared with the thrombolysis in myocardial infarction (TIMI) grading scheme used for evaluation of cardiac cases. ${ }^{59}$ This new system takes into consideration collateral circulation. It consists of six grades of classification, summarized in Table 2. The IA approach is believed to have the advantage of delivering thrombolytic agents to the thrombus in high concentrations locally. Theoretically, this allows lower systemic dose and assumed lower hemorrhagic complication rates; it also allows the simultaneous use of mechanical disruption to facilitate thrombolysis. ${ }^{60-62}$

Furthermore, it reduces the dose of thrombolytics to which the patient is exposed, which helps minimize the neurotoxic deleterious effects of these agents. ${ }^{63}$ Prourokinase was mainly studied for IA thrombolysis in the mid-1990s. The Prolyse in Acute Cerebral Thromboembolism (PROACT) trial evaluated IA pro-urokinase (6 $\mathrm{mg}$ ) versus placebo for the treatment of middle cerebral artery (MCA) occlusion within $6 \mathrm{~h}$ of symptom onset. ${ }^{64}$ There was a $10-12 \%$ absolute increase in excellent neurological outcome at 90 days in patients who received pro-urokinase compared with placebo. The rate of symptomatic hemorrhages within the first $24 \mathrm{~h}$ was $15.4 \%$ in the pro-urokinase group versus $7.1 \%$ in the placebo group. Later, a phase III multicenter study was performed; the PROACT II trial compared patients who received IA infusion of pro-urokinase $(9 \mathrm{mg})$ and low- dose heparin versus low-dose heparin for treatment of an angiographically proven MCA occlusion in the 6-h window of onset. ${ }^{65}$ It was found that there was a $15 \%$ absolute increase in favorable outcome with IA prourokinase use, translating to a number needed to treat of seven to achieve benefit for one patient. The rate of symptomatic hemorrhagic transformation within $24 \mathrm{~h}$ was $10 \%$ in the pro-urokinase patients versus $2 \%$ in the control group.

The potential time delay required to obtain the cerebral angiography and place the microcatheter in proper position to administer the thrombolytic agent is a disadvantage of this modality; hence, the idea of combining IV thrombolysis with the IA approach. The Emergency Management of Stroke (EMS) Bridging trial was a randomized, double-blind, placebo-control study which demonstrated a higher recanalization rate $(53 \%)$ in the combined IV/IA alteplase treatment group versus the IA alteplase group (28\%). ${ }^{66}$ No clear difference was observed in clinical outcomes between the two groups, nor was there any significant difference in the rate of symptomatic intracranial hemorrhage (ICH). This suggested the feasibility of the approach. Bridging is favored in a subset of patients who are expected to have a limited response to IV treatment such as those with severe neurological deficits, presentation between 3 and $6 \mathrm{~h}$ of symptom onset, history of major surgery within the last 14 days, and occlusion of major cervical or intracranial vessels with a high National Institute of Health stroke scale (NIHSS) score. ${ }^{42}$

The mechanical devices used for treatment of stroke can be classified in two main groups: 1) mechanical disruption devices such as snares, balloon-mounted stents, Mitsui \& Co. Venture Partners, Inc./MicroLysUS infusion catheters (EKOS Corp., Tokyo, Japan), ${ }^{67}$ An- 


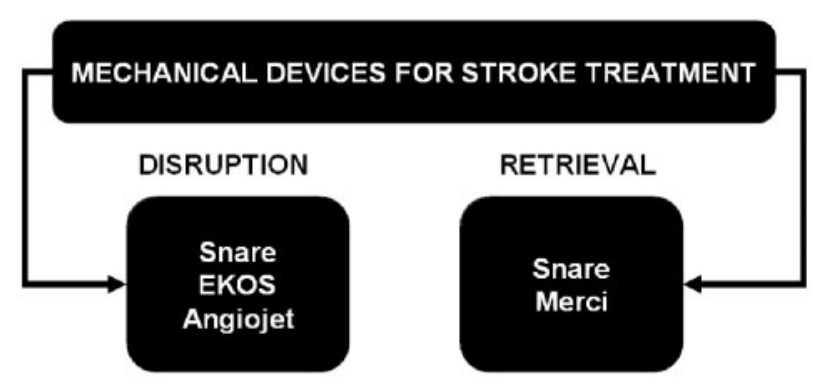

FIG. 3. Mechanical devices for treatment of acute ischemic stroke could be broadly categorized into mechanical disruption and retrieval devices. The figure outlines a few of the available devices categorized in two broad classes. Note that the snare device could be used for either and is probably the most popular device for acute ischemic stroke intervention.

giojets, ${ }^{68}$ and Neurojets; and 2) mechanical clot retrieval devices such as the Merci Retrieval System (FIG. 3). ${ }^{69}$

The snare device is a microwire with a distal coil loop and a nitinol shaft shaped at 90 degrees. ${ }^{70}$ It is available in various sizes and lengths and can be used for disrupting the clot mechanically, or in some instances for retrieving the clot. Kerber et al. ${ }^{71}$ reported that the snare device offers additional or alternative therapy for stroke patients who do not respond to pharmacological thrombolysis either IV or IA and suggested that immediate removal of a clot could reduce the total time of brain ischemia more rapidly than administration of thrombolytics.

Stents are metallic structures that help maintain the patency of the vessel. Stents were named after an English dentist who invented this device in the late 19th century; the name was later used by plastic surgeons for support in molding of tissues. ${ }^{72}$ A group of investigators from Buffalo, NY. reported the use of intracranial balloonmounted stents for acute ischemic stroke treatment in four patients. ${ }^{73}$ The site of occlusion in three of four patients was the MCA-the other was in the basilar artery; ages ranged from $46-88$ years of age. A TIMI grade III recanalization was achieved in three patients; the fourth patient had a TIMI grade II. It should be emphasized that when resorting to this method of treatment, patients should be preoperatively treated with aspirin and clopidogrel, or alternatively with IV abciximab, to counteract the thrombogenicity of the stent. The same group recently reported emergency stent placement in the setting of an acute carotid artery occlusion after endarterectomy. The authors concluded that using stents is an alternative method for treatment of acute carotid artery occlusion or dissection after carotid endarterectomy. ${ }^{74}$

Stent placement may lead to a robust cellular response, and intimal hyperplasia ${ }^{63,75}$ that may result in restenosis of the affected area. This was seen in about $30 \%$ of coronary percutaneous interventions. ${ }^{76}$ Therefore, much effort has focused on developing drug-eluting stents ca- pable of decreasing the incidence of restenosis and thrombosis. ${ }^{63}$ Materials used to coat the stents include polytetrafluoroethylene, titanium-nitride-oxide, rapamycin (sirolimus; Wyeth-Ayerst, Princeton, NJ), taxol (paclitaxel; Bristol-Myers Squibb, New York, NY), and phosphorylcholine. ${ }^{63}$ Rapamycin-coated stents are effective in reducing in-stent stenosis. Rapamycin forms a complex at the tacrolimus-binding protein which results in inhibition of protein synthesis and receptor signaling. ${ }^{77,78}$ Paclitaxel inhibits proliferation by affecting microtubule formation. ${ }^{63}$

Possis Angiojet (Possis Medical, Inc., Minneapolis, $\mathrm{MN}$ ) is a small rheolytic microcatheter device that fragments clots by using high-pressure, pulsed saline to create a low-pressure venturi effect. Suctioning of debris is achieved through the catheter lumen. ${ }^{63}$ The Angiojet device has been used with success in coronary interventions for acute myocardial infarction associated with extensive intracoronary thrombus. ${ }^{79,80}$ Bellon et al. ${ }^{68}$ published their experience in treating three patients with large thrombi of the ICA using a rheolytic thrombectomy device. The authors concluded that it was a promising modality for treatment of such cases allowing expedient access to the intracranial circulation for additional thrombolytic therapy. Neurojet is a modified version of Angiojet. ${ }^{81}$

The EKOS MicroLysUS (Mitsui \& Co. Venture Partners, Inc./Ekos Corp.) catheter is a 2.5 French standard infusion microcatheter with a $2 \mathrm{~mm}$, and a $2.1-\mathrm{MHz}$ ring sonography transducer at its distal end. ${ }^{67}$ It generates a 360-degree circumferential pulse wave around the tip and delivers IA thrombolytics in conjunction with ultrasound energy at the site of the clot. The use of this device was reported by Mahon et al. on 14 patients with anterior or posterior circulation cerebral ischemia $3-6$ or $4-13 \mathrm{~h}$ after symptom onset, respectively. Simultaneous IA thrombolysis and sonographic transmission were used. A TIMI grade $2-3$ flow was achieved in 8 of 14 patients studied, with no adverse reactions related to the catheter. It was concluded that use of the EKOS MicroLysUS catheter in the treatment of acute embolic stroke appeared to be safe and effective. A large-scale clinical trial seems warranted.

The Merci Retrieval System (Concentric Medical, Inc., Mountain View, CA) has three main parts: 1) the Merci Retriever; 2) the Merci Balloon Guide Catheter (BGC); and 3) the Merci microcatheter. ${ }^{69}$ The Merci Retriever, a tapered wire with five helical loops of decreasing diameter at its distal end, utilizes the superelastic property of previously shaped nitinol. The Retriever is advanced through the microcatheter in a straight configuration and resumes its helical shape once it is delivered into the occluded artery where it captures the clot. In a recently published study, 28 acute ischemic stroke patients were treated with the device within an 8-h window from 
symptom onset. Successful recanalization was achieved in $43 \%$ of patients. Eight patients received IA tissue plasminogen activator after mechanical recanalization efforts failed. The combined use of mechanical clot retrieval with pharmacological thrombolysis increased the number of patients with successful recanalization to 18 (64\%) patients. No symptomatic intracranial hemorrhages were reported. This study showed that the Merci device was safe and beneficial for embolectomy in a significant number of patients, even when performed in an extended 8-h window. ${ }^{69}$

The Endovascular Photo Acoustic Recanalization (EPAR) laser system (EndoVasix, Inc., Belmont, CA) converts photonic energy into acoustic energy at the fiberoptic tip; the acoustic energy then emulsifies the thrombus inside the tip of the catheter and the contents are subsequently discharged as minute particles that are subcapillary in size. ${ }^{82}$ A prospective, nonrandomized trial conducted in six centers within the United States, Canada, and Germany enrolled 34 stroke patients presenting within $6 \mathrm{~h}$ from projected EPAR system treatment in the anterior circulation, and within $24 \mathrm{~h}$ in the posterior circulation. ${ }^{82}$ Ten of these patients had ICA occlusion, 12 had MCA occlusion, 11 had vertebrobasilar occlusion, and one had posterior cerebral artery occlusion. The recanalization rate was approximately $41 \%$, and symptomatic ICH occurred in $5.9 \%$ of the patients. Thirteen patients had additional treatment with IA rtPA. This new technique appears to be safe and may provide an alternative treatment for acute ischemic stroke.

\section{Carotid stenosis}

Accumulating evidence that has shown the benefit of carotid endarterectomy in reducing the risk of stroke and death in patients with moderate-to-severe symptomatic (greater than $50 \%$ ) or asymptomatic (greater than or equal to $60 \%$ ) carotid artery stenosis. ${ }^{83,84}$ A randomized trial of endarterectomy for recently symptomatic carotid stenosis, the European Carotid Surgery Trial (ECST), proved beneficial..$^{85,86}$

Selective surgical trials were conducted with comparison to best medical therapy in a controlled manner. Inclusion and exclusion criteria were such that high-risk patients were omitted from the study population. Since carotid endarterectomy has become widely practiced in the United States, high-risk patients have been received surgery. Perioperative complication rates have exceeded the potential benefits in general practice. This is especially true in patients with unfavorable clinical and anatomical characteristics. ${ }^{87-91}$

Dotter and Judkins ${ }^{92}$ initiated percutaneous revascularization procedures in 1964. Almost a decade later, the Gruntzig balloon catheter was successfully developed for peripheral balloon angioplasty. ${ }^{93}$ By 1980 , Mullan et al. ${ }^{94}$ used the Gruntzig balloon catheter to perform one of the first successful carotid angioplasties on a patient with fibromuscular dysplasia. During the 1980s, a series of papers was published with a small number of subjects. During that time, it was felt that carotid endarterectomy was being overused as treatment for carotid disease. The principal reason was the popularity and evidence to show that surgical endarterectomy was helpful for the treatment of carotid disease. Carotid angioplasty with stent placement (CAS) was resurrected as an alternative treatment for revascularization of carotid artery stenosis in high-risk surgical candidates. ${ }^{95}$ More recently, several nonrandomized studies and randomized comparisons with carotid endarterectomy have increased the popularity of CAS. These studies have focused on the safety and effectiveness of CAS. With improving devices and techniques, CAS has become safer than and at least as effective as surgical treatment. ${ }^{96,97}$ Studies have strongly advocated the use of a distal protection device in highrisk surgical patients.

In the Study of Angioplasty with Protection in Patients at High Risk for Endarterectomy (SAPPHIRE), 307 high-risk patients were allocated to carotid endarterectomy or CAS. In this study, 402 patients were considered unsuitable for carotid endarterectomy and were directly involved in a stent registry. The 30-day follow-up showed a combined rate of death, stroke, or myocardial infarction was significantly lower for patients who had CAS and distal protection (6\%) compared with patients who received carotid endarterectomy (13\%). The combined rate of death, stroke or myocardial infarction was $8 \%$ in patients enrolled in the stent registry. At 1 year, ipsilateral stroke was $3.8 \%$ for the patients receiving CAS and $5.3 \%$ for patients receiving endarterectomy. Overall, $6.9 \%$ of the patients who received CAS and $12.6 \%$ of those who received an endarterectomy had died by the first year.

A nonrandomized Acculink for Revascularization of Carotids in High-Risk Patients study ${ }^{97}$ had a rate of $8 \%$ for combined endpoint death, stroke, or myocardial infarction at 30 days in high-risk patients included in the study. In total, there were 437 patients recruited. The subset analysis revealed that patients with restenosis can be treated with a minimal risk of stroke or death (less than $1 \%)$.

Progressive improvements in technology and increasing operator experience and encouraging results from clinical trials have led to a broader acceptance of CAS even in patients not considered high risk for carotid endarterectomy. In a multicenter randomized Carotid and Vertebral Artery Transluminal Angioplasty Study (CAVATAS), 251 patients randomly assigned to endovascular treatment had a rate of stroke or death which was almost the same as that of 253 patients allocated to carotid endarterectomy ( $6 \%$ vs 6\%). In the CAS group, a higher rate of restenosis was seen at 1 year $(18 \%)$ then 
after carotid endarterectomy $(5 \%, p<0.001) .{ }^{98}$ There was a high risk of complications including cranial neuropathies and major neck hematomas in patients assigned to carotid endarterectomy.

The National Institute for Neurological Disorders and Stroke in collaboration with private pharmaceutical groups sponsored the Carotid Revascularization Endarterectomy Versus Stent Trial (CREST).$^{99}$ CREST compared the efficacy of CAS with carotid endarterectomy in a lead-in phase which was set up to do 20 CAS procedures for the four randomizing patients. The review of 169 patients treated in the lead-in phase reported a combined rate of death, stroke, or myocardial infarction within 30 days after the procedure of $4 \%$, suggesting equivalence for patients undergoing carotid endarterectomy. The lead-in phase data showed that the complication rate was high in octogenarians and therefore the age limit was lowered to below 75 years for enrollment. CREST plans to compare the efficacy of CAS with carotid endarterectomy in 2,500 patients with symptomatic stenosis and patients who are not considered a high surgical risk. ${ }^{99}$

Technique and medication use. Patients receive clopidogrel $75 \mathrm{mg}$ orally once daily for 5 days before the procedure; alternatively, the patient could be on ticlopidine $250 \mathrm{mg}$ twice daily also for 5 days. This is given in combination with aspirin $325 \mathrm{mg}$ orally for 5 days before the procedure. These medications were continued up to 1 month after the procedure. The data supporting the use of these medications are mainly derived from coronary intervention. Heparinization during the procedure to achieve Activated Clotting Time (ACT) of approximately $300 \mathrm{~s}$ or above is done before undertaking CAS. IA papaverine (50-100 mg) and/or nitroglycerin (200$400 \mu \mathrm{g}$ ) may be administered in the target artery to reduce arterial spasm before and during angioplasty. Papaverine should not be used in an awake patient particularly in the posterior circulation. Patients who are on $\beta$-blockers before their procedure and those who have a localized bulb plaque may be given glycopyrolate, atropine or scopolamine to offset bradycardia and hypotension. ${ }^{100}$

The delivery and access for balloon angioplasty and stents are undertaken through a guide sheath placed in the common carotid artery proximal to the stenosis either through the femoral route or through the radial route. There are two classes of stents used. ${ }^{101}$ The balloon expandable stents are usually made of stainless steel, whereas the self-expanding stents are stainless steel or a thermal expansion alloy commonly known as nitinol.

At present other than the use of medications outlined above, the adjuvant use of platelet glycoprotein IIb/IIIa inhibitors in the perioperative and immediate postoperative period is controversial. ${ }^{102} \mathrm{~A}$ recently published small trial did not show any reduction in perioperative ischemic events during CAS when comparing abciximab to standard antithrombotic treatment (19\% vs $8 \%$, respectively). ${ }^{103}$

Distal protection device. It is well known that patients undergoing CAS have small embolic showers occurring frequently during the procedure that can persist with increased frequency compared with baseline for hours or days after the angioplasty. This has been shown using intraprocedural transcranial Doppler imaging (TCD). ${ }^{104,105}$ It is also known that these microemboli are composed of thrombotic and plaque substances. ${ }^{106} \mathrm{Mag}$ netic resonance imaging (MRI) had suggested that about $15 \%$ of patients developed new ischemic lesions based on diffusion-related abnormalities in the brain after this procedure. ${ }^{107} \mathrm{~A}$ similar study suggests that almost half of these patients remain asymptomatic. From previous data on carotid endarterectomy, it appears that the rate of new brain lesions is higher in CAS than the rate reported for endarterectomy at 5\%. ${ }^{108}$ This underlies the importance of using a distal protection device to prevent the microemboli from being released into cerebral circulation during carotid angioplasty and stenting.

The techniques for distal protection during CAS were pioneered by Theron and others. ${ }^{109}$ The techniques vary but usually involve either a parallel or coaxial catheter system. One catheter system occludes or filters the distal artery and the other performs the angioplasty. Resulting debris from the procedure is flushed or aspirated from the ICA proximal to the protective balloon before deflation. There are ongoing trials looking at role of distal protection as an adjunct to carotid angioplasty and stenting. Investigators have reported a substantial reduction in embolic and other complication rates during CAS using protection devices and techniques. ${ }^{96,97,110-113}$

Distal protection devices include occlusive balloons, filter devices, and flow reversal devices (FIG. 4). The low-pressure occlusion balloon is placed distal to the site of CAS to trap the blood flow and the embolic material before entering the intracranial circulation. Filtration devices work similarly and are placed intravascularly distal to the site of intervention to filter the blood and retain any embolic debris. The third system consists of a guiding catheter with an occlusion balloon that induces reversal of intracranial fluid to prevent intracranial flow of emboli. Figures 5 and 6 demonstrate the use of distal protection devices for the posterior circulation (FIG. 5) and anterior circulation (FIG. 6). Figure 6F also shows the emboli captured by the device.

\section{Intracranial and vertebral artery stenosis}

Intracranial stenosis is responsible for $8-10 \%$ of all ischemic strokes. ${ }^{102,114}$ There is an astoundingly high yearly rate of recurrent strokes in patients with intracranial stenosis that has been estimated at approximately $8-12 \% .{ }^{115,116}$ For those patients not responding to anti- 


\section{DISTAL PROTECTION}

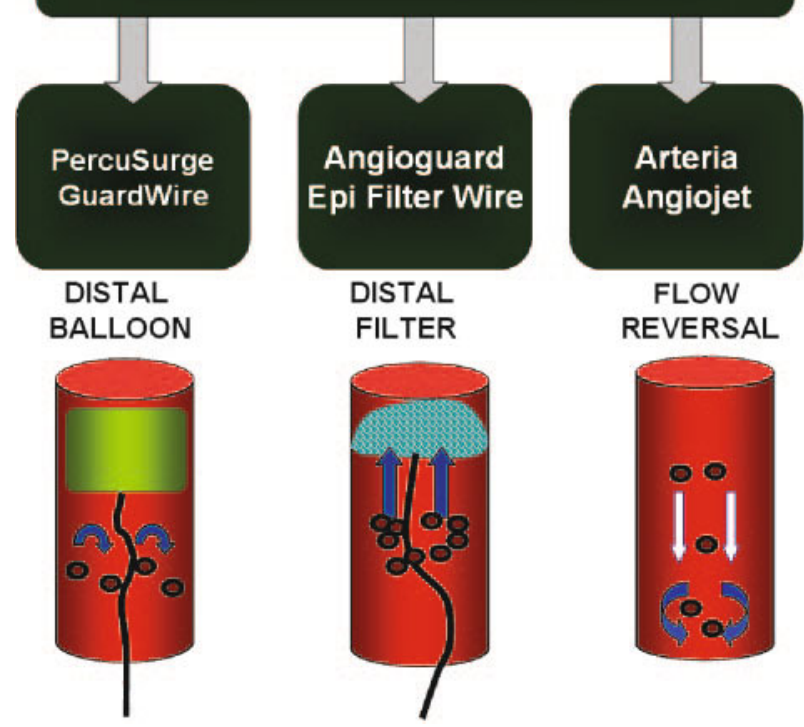

FIG. 4. Examples of distal protection devices for the prevention of embolic debris causing distal vasculature strokes. The figure also depicts the cartoons depicting the mechanism for each type of filter.

thrombotic treatment, the rate of recurrent ischemic stroke events can be even higher and has been estimated at $52 \% .{ }^{117}$ Patients with symptomatic vertebrobasilar stenosis had a low stroke-free survival rate of $76 \%$ at 12 months and $48 \%$ at 5 years. ${ }^{102}$

The diagnostic evaluation of patients with intracranial stenosis presenting with symptoms of ischemic stroke is highly dependent on the technological capabilities at individual centers. With continuing advancement of TCD, MRI, and computerized tomography, there is better visualization of intracranial vasculature. The greatest disparity between MRI and conventional angiography occurs in lesions in the proximal vertebral artery. ${ }^{118}$ Velocities may possibly be accelerated in TCD depending on the nature and anatomy of the stenosis and the vasculature. Some studies have reported high false-positive rates of $20 \%$ for symptomatic and $41 \%$ for asymptomatic lesions using with neurosonology criteria alone. The rate remains high even when combined with MRI for carotid artery stenosis measurement when compared with cerebral angiography. ${ }^{119}$ As less invasive means of identifying intracranial and vertebral artery stenosis continue to improve, the need for angiography may be obviated in select cases. However, at this point, for accurate measurement of posterior circulation stenosis and intracranial stenosis, cerebral angiography is still considered the gold standard.

Percutaneous transluminal angioplasty. Percutaneous transluminal angioplasty (PTA) with possible stent placement has been recommended for treatment of intracranial stenosis especially for patients not responding to antithrombotic treatment. Also, the patients who have vertebrobasilar stenosis of extracranial vessels and fall into the same category would be eligible for consideration of transluminal angioplasty with stent placement. ${ }^{120}$ Small patient series have shown the feasibility of stent placement with angioplasty for symptomatic intracranial stenosis, with major complication rates of less than 5\%..$^{121-123}$ The long-term follow-up has suggested ipsilateral stroke prevention of up to $96 \%$ for the first year and approximately $87 \%$ for up to the third year after interventional treatment. $^{121}$

The prospective multicenter Stenting in Symptomatic Atherosclerotic Lesions of Vertebral Intracranial Arteries (SSYLVIA) study ${ }^{120}$ assessed 43 patients with intracranial stenosis and 18 with extracranial vertebral artery stenosis. The technical success rate was $95 \%$ with 1-month postprocedural stroke rate of $7 \%$. At 6 months, recurrent stenosis of greater than $50 \%$ was reported in $30 \%$ of the intracranial arteries. Of the 42 patients with 12-month follow-up, four suffered a stroke after 30 days that was related to the target lesion.

Restenosis and stent improvements. Restenosis, particularly in the small caliber blood vessels including intracranial vessels and extracranial vertebral arteries, remains a problem. Drug-eluting stents have been developed for coronary intervention and have been shown to reduce rates of restenosis. ${ }^{124,125}$ The drug-eluting stents are designed to target intimal proliferation and subsequent restenosis by delivery of an anti-inflammatory and/or antimitotic agent. There are two commercially available stents that have successfully prevented coronary restenosis. ${ }^{126}$ Cypher (Cordis Corp., Miami, FL) elutes sirolimus, a combination of an anti-inflammatory and an antimitotic agent. ${ }^{127}$ The other stent is Taxus (Boston Scientific Corp., Natick, MA) that elutes a drug paclitaxel, an antimitotic agent. ${ }^{63}$

The recent improvement in stent designs and delivery of coated agents has reduced neointimal proliferation and restenosis. ${ }^{126}$ There have been similar problems of restenosis in intracranial atherosclerotic disease and vertebral artery disease. The rate of restenosis seems to be directly dependent on the diameter of the blood vessel. Recently, there have been case reports on the use of intracranial drug-eluting stents.

Future developments such as intracranial balloons and stents specific for atherosclerotic lesions with greater radial force such as the Wingspan (Boston Scientific) angioplasty and stent system could also further advance intracranial angioplasty and stenting. It is expected that in the future a combination of mechanical protection devices and better designed stent delivery systems, as well as drug-coated stents, should help to reduce perioperative and postoperative complication rates. Examples of successful neurological applications are demonstrated 

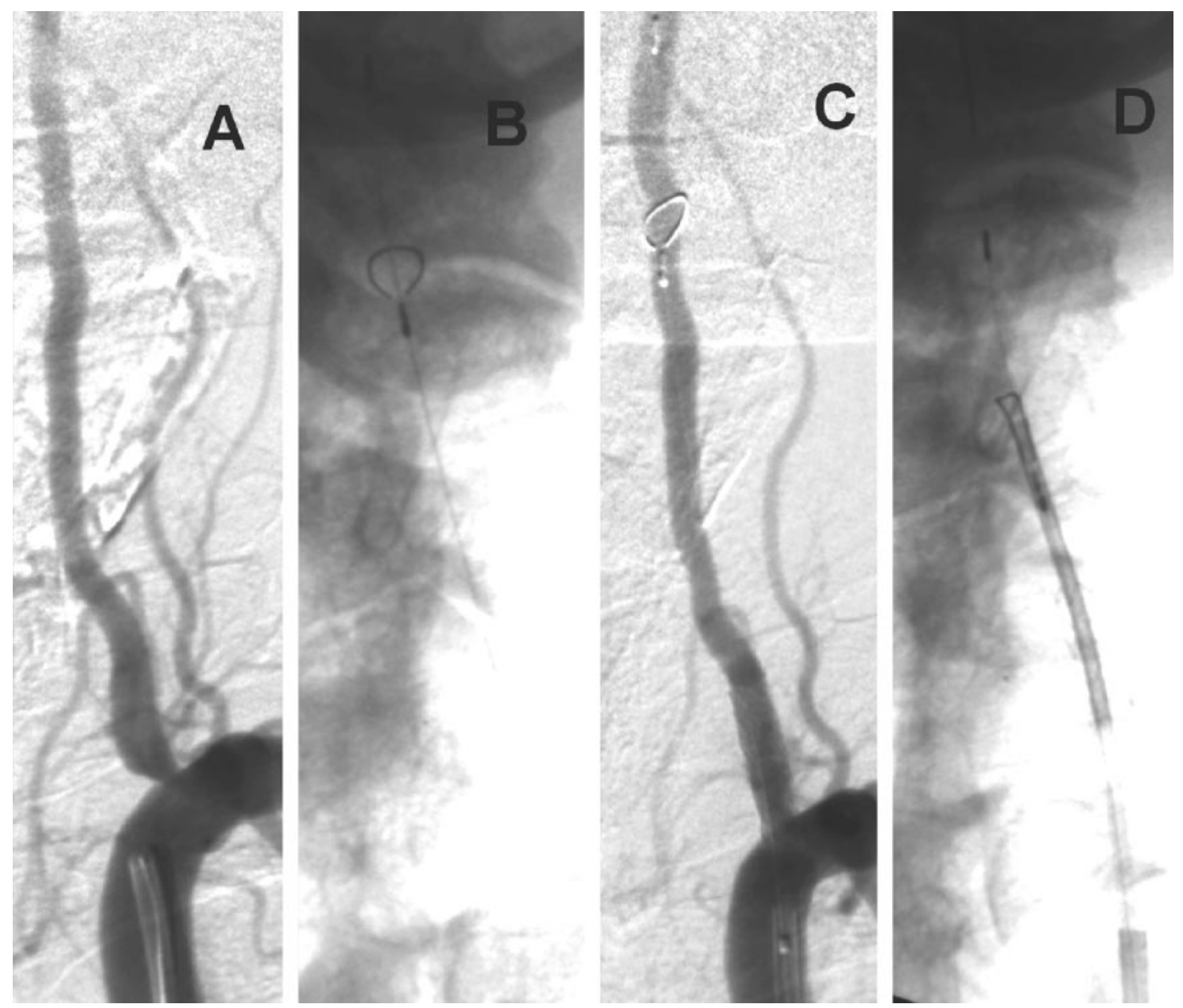

FIG. 5. A case illustration of vertebral origin stenting through a radial route using a distal protection device. A: Vertebral artery origin stenosis. B: Deployed distal protection device (EpiFilter wire) and stent is seen in unsubtracted digital angiography. C: Flow of contrast post-angioplasty and stent. The distal protection device is eventually recaptured using a 4 French multipurpose catheter.

in Figures 5 (Cypher stent system) and 8 (Taxol stent system).

\section{Dural sinus thrombosis}

Dural sinus thrombosis (DST) is an infrequent but important disorder that must be recognized and promptly treated. ${ }^{128}$ The mortality rate associated with this condition is high, ranging from $5-30 \%$. DST also includes thrombosis of cortical and deep cerebral veins. ${ }^{129}$ The clinical features of DST are nonspecific, varying from mild headache and focal neurological signs to a catastrophic progressive increase in intracranial pressure leading to neurological deterioration and death. ${ }^{128,129}$ The interruption of outflow in the brain circulation leads to augmentation in the pressure of the entire system with venous hypertension, intracranial hypertension, and hemorrhagic events.

Several conditions predispose to DST: trauma, neoplasms, and other mass lesions can cause vascular compression and altered hemodynamics, leading to DST. Hypercoagulable states like malignancies, lupus, and other conditions are also associated with DST. ${ }^{130}$ Infection may induce sinus thrombosis.

Usually, the outcome is closely related to initial clinical picture. Patients presenting with headache and papilledema alone have good prognoses. ${ }^{131}$ Underlying cause may also influence the outcome. ${ }^{132}$ Smith et al. ${ }^{133}$ described rapidity of onset, early reduced Glasgow outcome scale, focal neurological signs, seizures, and concomitant infection as indicators of a poor prognosis. Due to its relative rarity and variable clinical and imaging features, ${ }^{129}$ the key for the diagnosis is a high level of suspicion.

The treatment of choice for DST remains controversial. The main goal of the treatment of DST should be the recanalization of venous drainage system with complete reestablishment of normal brain circulation. ${ }^{128,130}$ In most centers, including ours, the treatment of choice is IV anticoagulation followed by local thrombolysis where indicated. A nonrandomized study ${ }^{130}$ of 40 consecutive patients studied the safety and efficacy of two treatments 

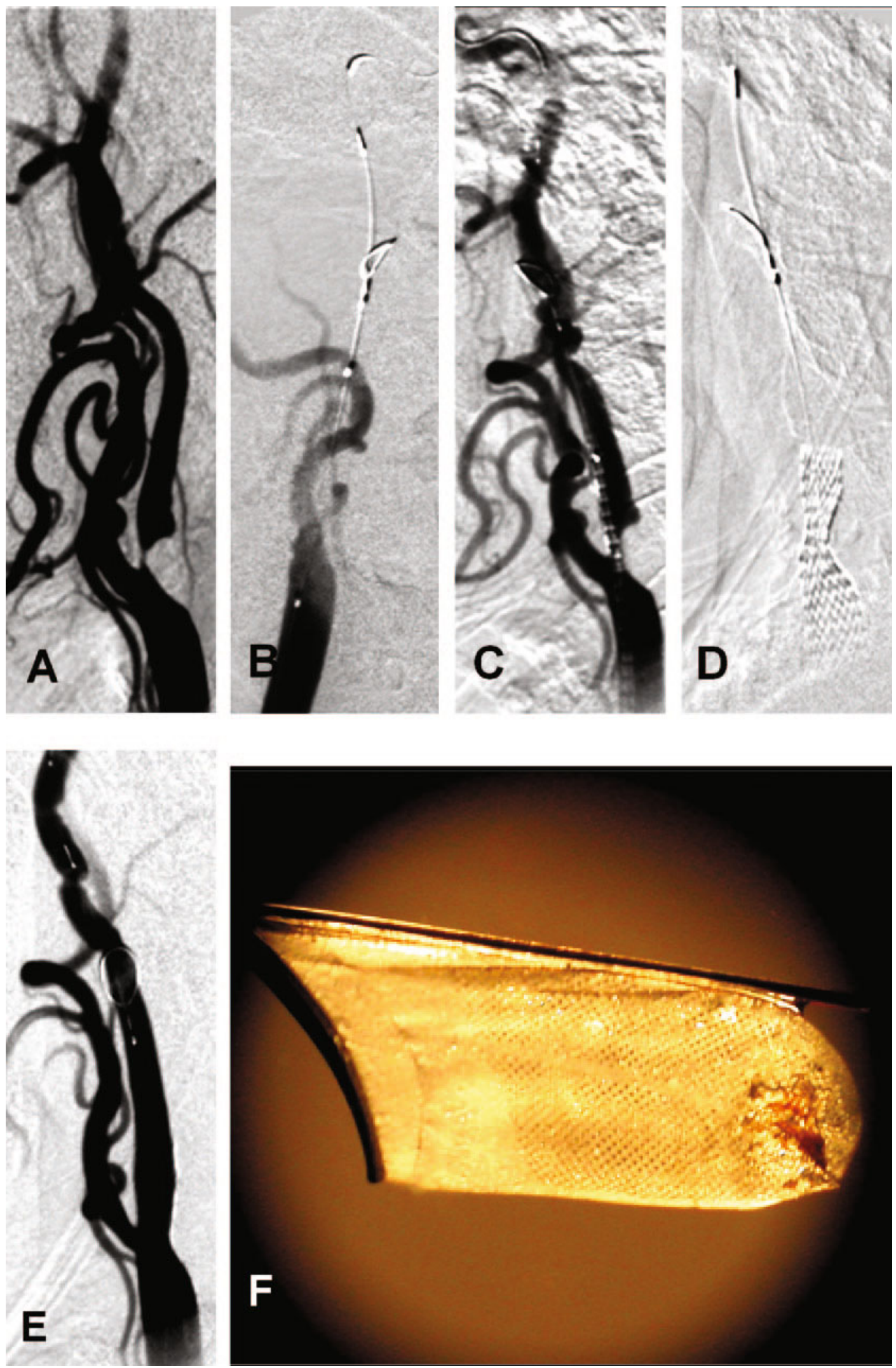

FIG. 6. Case illustration depicting carotid angioplasty and stenting using a distal protection device. A: Near-occlusive high grade stenosis of the right internal carotid artery at its origin. B: Angioplasty balloon across the lesion with a distal protection device in place for the angioplasty. C: Stent across the lesion. D: Deployment of the stent. E: Frame of an angiogram run after stenting and angioplasty and final results with a residual stenosis of less than 15\%. F: Demonstration of debris collected by the EpiFilter device. 

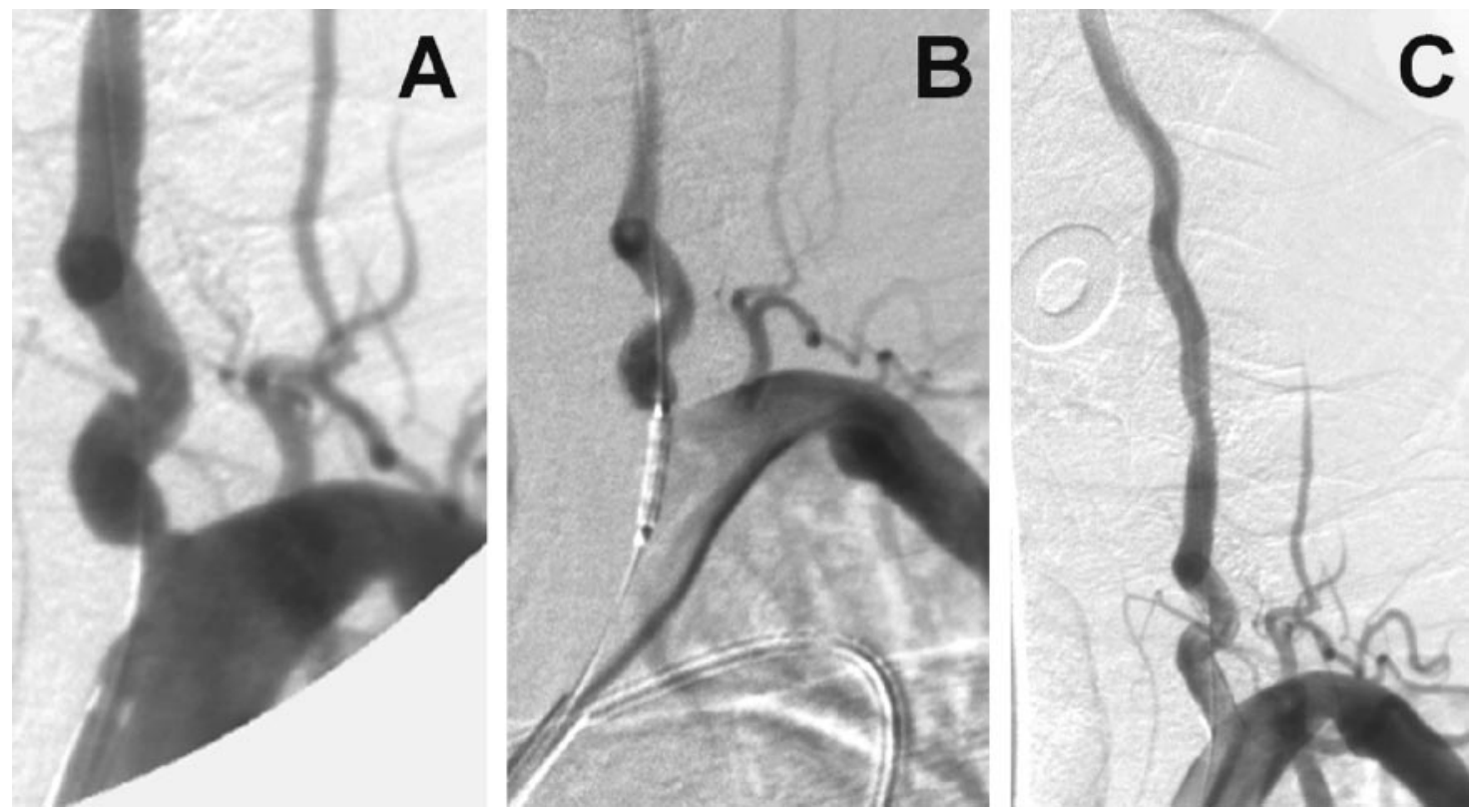

FIG. 7. Case illustration of vertebral artery origin stenting in a patient who had an atretic contralateral vertebral artery and has continued to have transient posterior circulation ischemic events despite best medical therapy. A: Extent of stenosis. B: Stent across the area of stenosis. C: Results after angioplasty and stenting.

for superior sagittal sinus (SSS) thrombosis. The Thrombolysis Group $(n=20)$ received local urokinase into the SSS followed by IV heparin anticoagulation. The Heparin Group $(\mathrm{n}=20)$ received IV heparin anticoagulation only. Neurologic outcome at discharge from the hospital was better in the Thrombolysis Group $(p=0.019)$. Hemorrhagic complications were $10 \%(\mathrm{n}=2)$ with urokinase (subdural hematoma, retroperitoneal hemorrhage) and none with heparin alone $(p=0.49)$. Three of the heparin patients but none of the urokinase patients developed

A
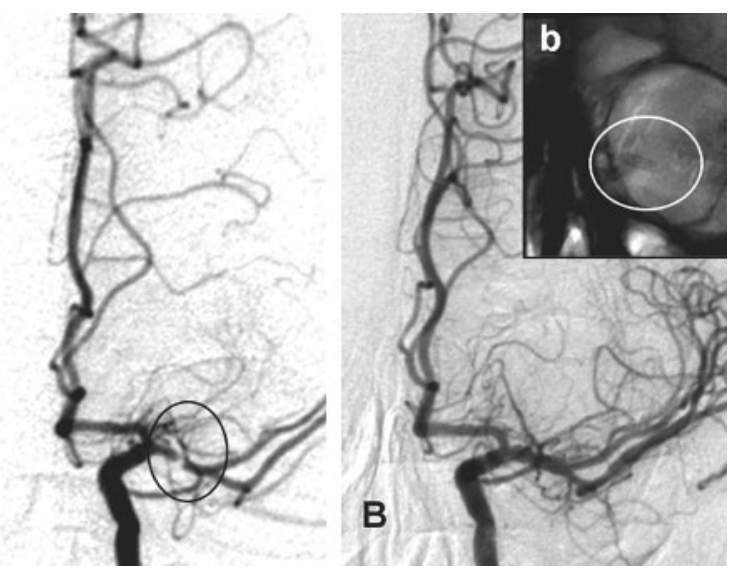

FIG. 8. This is an example of a drug (paclitaxel) eluting stent in the middle cerebral artery of a patient with recurrent ischemic symptoms despite best medical therapy. The patient was symptom free at 3 months of follow-up with a normal neurologic exam. A high-grade stenosis seen in the trunk (M1) of the middle cerebral artery (A) (highlighted by a black circle) was successfully angioplastied and stented to get the results seen (B). Inset b: Unsubtracted angiogram and the struts of the stent within the confines of orbital ridges as highlighted by the white circle. complications of the underlying disease. The authors concluded that local thrombolysis with urokinase was fairly well tolerated and may be more effective than systemic heparin anticoagulation alone in treating DST. Fink et al. ${ }^{134}$ reported their experience with heparin, showing the safety of this drug even in cases presenting with intracerebral hemorrhage. Even though their series represents a small, nonrandomized, retrospective sample, this study is consistent with several prior reports and supports the safety of treatment of patients with cerebrovenous thrombosis with IV heparin, even in the presence of large ICH located in the temporal lobe. In our institution, we reserve the endovascular approach for patients who demonstrate clinical worsening despite adequate IV anticoagulation and treatment of the underlying etiology. Those patients presenting with a contraindication for systemic anticoagulation should also be considered for local thrombolysis.

The endovascular route used is transvenous through the femoral vein, navigating the catheter into the venous circulation and final placement in the matrix of thrombus. The thrombolytics are infused over a period of hours for a better recanalization. The rate of recanalization (partial and total) ranges from 70-95\%. ${ }^{130,135-140}$ There is a low risk of ICH complications in published series.

Small case series have documented the use of mechanical devices to facilitate the thrombolytic process. Chaloupka et al. ${ }^{138}$ described the use of microballoon transluminal angioplasty in a case of SSS occlusion resistant to urokinase. Malek et al. ${ }^{139}$ reported the use of angioplasty and stenting in a case of pansinus thrombosis 


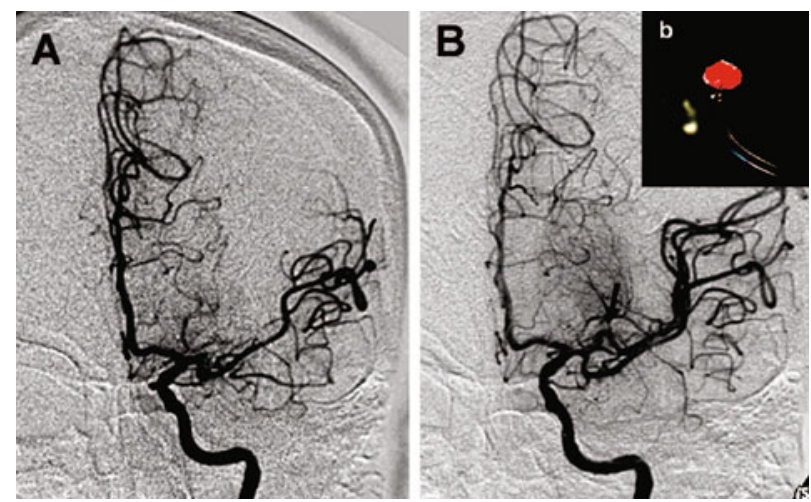

FIG. 9. This is a case illustration of a snare device able to disrupt and ultimately retrieve part of a presumably very large clot in this elderly woman with a large middle cerebral artery (MCA) stroke. The angiographic results are shown before (A) and after (B). B: Superior division of MCA is open. Inset b: Actual clot is shown hanging from tip of the snare device.

refractory to anticoagulant therapy, which led to sustained venous outflow. A rheolytic thrombectomy catheter, Angiojet (Possis Medical, Minneapolis, MN), has been described as a useful adjuvant to IA pharmacological intervention in some cases. ${ }^{141,142}$ Figure 9 illustrates a case of acute ischemic stroke where recanalization was achieved using a combination of thrombolytics and snare device. The snare was able to retrieve a fresh clot that is also illustrated in the inset of Figure 9.

\section{Cerebral vasospasm}

Despite considerable advances in diagnostic, surgical, endovascular and anesthetic techniques, as well as perioperative management, the outcome for patients with SAH remains poor, with overall mortality rates of $25 \%$ and significant morbidity among approximately $50 \%$ of survivors. ${ }^{1,2}$

Despite all therapeutic possibilities, a large number of patients develop angiographic or clinical vasospasm responsible for high morbidity and mortality. Early aneurysm surgery followed by hypervolemic, hypertensive therapy has been the treatment of choice to prevent and treat this clinical and neuroimaging entity. Pharmacological treatment with calcium channel blockers has been shown to improve the final outcome. ${ }^{143}$ In 1987, the Cooperative Aneurysm Study reported an incidence of angiographic vasospasm of more than 50\%, with symptomatic vasospasm of $32 \%$ in 1378 patients with SAH at 71 centers. ${ }^{144}$ These values have remained consistent with contemporary retrospective reviews. ${ }^{145,146}$

In a small subset of patients, early vasospasm can be seen immediately after SAH. Usually the vasospasm is delayed and has a typical temporal course, with onset 3-5 days after the hemorrhage, maximal narrowing at 5-14 days, and gradual resolution over 2-4 weeks. In about half the patients, vasospasm is manifested by the occurrence of a delayed neurological ischemic deficit which can lead to stroke, disability and death. In contemporary series, $15-20 \%$ of such patients suffer stroke or die from vasospasm despite maximal therapy. ${ }^{147}$ The delayed ischemic neurological deficit associated with symptomatic vasospasm usually appears shortly after the onset of angiographic vasospasm with acute or subacute development of focal or generalized symptoms and signs. ${ }^{148}$ Progression to cerebral infarction occurs in approximately $50 \%$ of symptomatic cases; recovery without deficit in the remaining individuals may occur despite the persistence of angiographic vasospasm.

Endovascular therapy offers an additional treatment for patients who continue to experience delayed ischemic neurological deficits despite optimal medical therapy. It is preceded by a neuroimaging study to ensure that no large hemorrhage, hydrocephalus, or recent infarction is present. Close monitoring of intracranial and cardiac hemodynamics is performed. Once transferred to the angiography suite, heparinization is performed and maintained during the procedure. Presently, the most commonly employed treatments are PTA and/or intraarterial vasodilation with nicardipine, verapamil, nimodipine, amrinone, or milrinone. ${ }^{149}$

Percutaneous transluminal angioplasty. With the availability of smaller balloons and more navigable catheters almost all vessels can undergo PTA. The mechanism of action of balloon angioplasty is poorly understood. At the cellular level, it is thought that fragmentation of collagen fibers and myocytes results in permanent restoration of vessel diameter. ${ }^{146}$ Because the effects of PTA seem to be more sustained, this is the preferred treatment. It is, however more effective in treating larger proximal segments of vessels. Balloon angioplasty has been associated with complications including aneurysm rupture if incompletely obliterated, vessel rupture or thrombosis, and reperfusion hemorrhage. ${ }^{147}$ An example is shown in Figure 10.

Intra-arterial papaverine. Papaverine injection is achieved with small repeated injections after superselective catheterization with a microcatheter positioned just proximal to the affected area of the vessel. ${ }^{148}$ Papaverine hydrochloride is an alkaloid manufactured synthetically. It acts on the smooth muscle cells through inhibition of cAMP phosphodiesterase activity, thereby increasing the levels of cAMP. It may also act by blocking calcium channels.

The results of endovascular papaverine therapy are derived from case series. Papaverine is usually reserved for the treatment of vessel segments inaccessible to PTA and when it is desirable to dilate distal segments of the vessels. The effect of papaverine is usually not sustained and a high rate of recurrence of vasospasm is observed. ${ }^{149-151}$

Use of papverine has been associated with a transient rise in intracranial pressure, and therefore it has been recommended to use intracranial pressure monitoring during infusion. Other reported complications include 


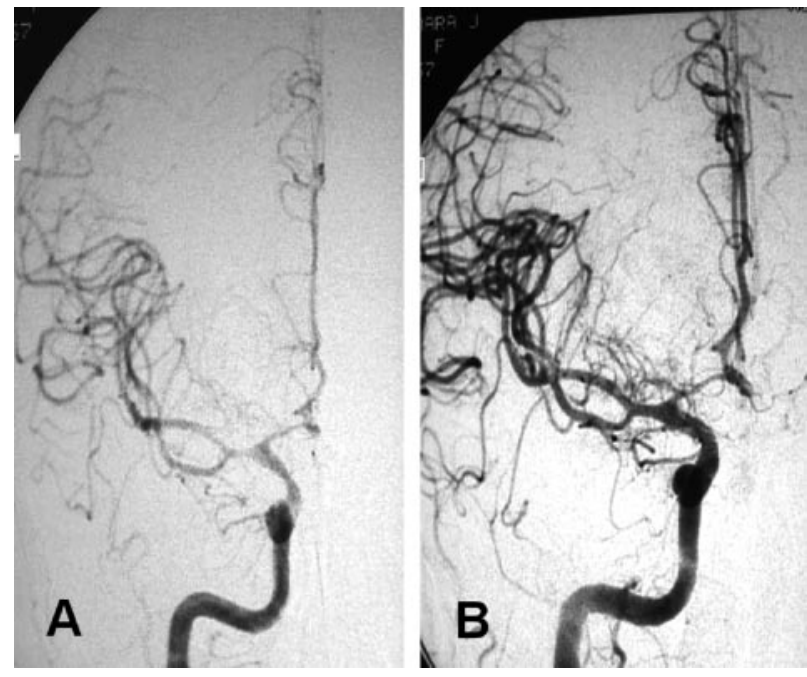

FIG. 10. Case illustration of 28-year-old man with subarachnoid hemorrhage; Hunt and Hess grade 3 and Fisher grade 3 at day 7. A: Cerebral vasospasm of the right middle cerebral artery and anterior cerebral artery after clinical deterioration. B: Improvement after emergent angioplasty, which led to clinical improvement.

the possible formation of crystal emboli causing monocular blindness, brainstem dysfunction with respiratory and hemodynamic compromise, and other focal neurological deficits that are usually transient. ${ }^{152}$

Improvements in neurointensive care monitoring and diagnostic studies have allowed rapid identification of patients who reach critical reductions in cerebral blood flow. The effect of endovascular treatment has been limited to documentation of improvement of vessel diameter, improvement of cerebral blood flow, and reversal of neurological deficits. With further experience and newer devices the complications related to treatment have decreased. A more rigorous assessment of the effects of the interventional approach for cerebral vasospasm in patients with SAH would require further trials. ${ }^{152}$

\section{Intracarotid amobarbital administration (Wada testing)}

Induced anesthesia of cerebral hemispheres is performed as a precursor to surgery for tumor or AVM resection or epilepsy treatment, to predict the risk for postoperative language and memory deficits. In 1948, Juhn Wada first described intracarotid injection of sodium amobarbital (IAT) for lateralization of language dominance, with his first reports appearing in the English literature in $1960 .{ }^{153,154}$ Since then, intracarotid Wada testing has been the standard for determining memory adequacy as well as language dominance. ${ }^{154,155}$ The rationale for this procedure involves the use of short-acting barbiturates, such as amobarbital or methohexital, ${ }^{156}$ that temporarily anesthetize the perfused region, thus isolating the contralateral hemisphere in performing cortical functions of language and memory. Angiographic tech- niques to catheterize the ICA are performed with subsequent instillation of 70-160 mg of barbiturate. Neuropsychological testing is then performed to assess language and memory function. Electroencephalography is often concurrently employed to assess cerebral activity before, during, and after anesthetization as another marker for absence and return of unilateral hemispheric function.

Whereas IAT is considered an integral element of epilepsy surgery planning, it has recently been criticized on an anatomic vascular basis as well as for having clinically inconsistent postoperative results. ${ }^{157}$ Sixteen years ago, to better predict potential postoperative memory deficits after temporal lobectomy, Jack et al. ${ }^{158}$ performed selective injections of sodium amobarbital into the posterior cerebral artery (PAT). Successful posterior cerebral artery (PCA) catheterization was performed in 38 of 45 patients $(84 \%)$ with one major complication $(2 \%) .{ }^{159}$ Subsequent reports of this technique have declined since that time, likely due in part to fear of complications. Since Jack's initial series, neuroendovascular materials and techniques have advanced considerably and we believe superselective PAT can be performed with minimal increased risk compared with IAT. A recent series of 14 patients again highlights the feasibility of superselective catheterization of the PCA for IA sodium amobarbital testing. ${ }^{160}$

Although amobarbital achieves good suppression of the gray matter, its effect on subcortical white matter tracts may be less profound. Fitzsimmons et al. ${ }^{161}$ reported superselective Wada testing of en passage blood vessels to AVM nidi using IA lidocaine, which suppresses white matter tracts, in addition to amobarbital. Limitations to superselective Wada testing during AVM embolization include the amount of time involved, detailed neuropsychological testing, and inability to perform such testing under general anesthesia, which is often requisite for entry into and embolization of tortuous and friable AVM vessels. However, a staged approach with preprocedural Wada testing followed by endovascular AVM treatment at a later date, similar to epilepsy surgery planning, is a feasible option.

\section{Future directions}

Endovascular therapy for acute and chronic cerebrovascular diseases and interventional neuroimaging is evolving at a rapid pace. The safety and efficacy of endovascular procedures is expected to improve with new technologies. New applications such as IA delivery of stem cells derived from bone marrow in autologous or transplanted stem cell delivery may help repair damaged regions of the brain. Although advances are constantly being made, further developments are needed to enhance techniques for cerebral protection during arterial recanalization. Techniques for preventing restenosis with the 
advent of drug eluting stents have already advanced at a rapid pace, and further developments in stent design would help to address the issue of restenosis in smaller diameter blood vessels. Further designs of devices for aneurysm obliteration and newer intracranial supportive stents might help for a more durable approach to aneurysm coiling. Biopolymer coated coils have been suggested to increase clot maturation and enhance intraaneurysmal fibrosis and thereby potentially decrease recanalization rates. A clinical trial comparing Guglielmi detachable platinum coils and biopolymer-coated platinum coils is being planned and might help better define the added benefit of coated coils to plain platinum coils. A combination of endovascular surgery in AVM treatment with rapidly advancing radiosurgery might make it possible for most AVMs to be treated in a minimally invasive manner in the near future. Improvement in AVM embolization may be possible with the development of liquid embolic agents.

Endovascular procedures are rapidly expanding as treatment options for cerebrovascular diseases and neoplasms and are becoming less invasive but more effective. It is essential to understand the scientific basis of treatment rationale based on advancing new neuroimaging techniques to better serve our patients.

\section{REFERENCES}

1. Plan and operation of the Third National Health and Nutrition Examination Survey, 1988-94. Series 1-Programs and Collection Procedures. Vital Health Stat 1, 32:1-407, 1994.

2. Detailed diagnosis and procedures, national hospital discharge survey, 1990. Hyattsville, MD: U.S. Department of Health and Human Services. DHHS publication, Series 13, 1992.

3. Rinkel GJ, Djibuti M, Algra A, van Gijn J Prevalence and risk of rupture of intracranial aneurysms: a systematic review. Stroke 29:251-256, 1998.

4. Werner SC BA, King BG. Aneurysm of the internal carotid artery within the skull: wiring and electrothermic coagulation. JAMA 116:578, 1941.

5. Hopkins LN, Lanzino G, Guterman LR. Treating complex nervous system vascular disorders through a "needle stick": origins, evolution, and future of neuroendovascular therapy. Neurosurgery 48:463-475, 2001.

6. Guglielmi G, Vinuela F, Sepetka I, Macellari V. Electrothrombosis of saccular aneurysms via endovascular approach. Part 1 : electrochemical basis, technique, and experimental results. J Neurosurg 75:1-7, 1991.

7. Stiver SI, Porter PJ, Willinsky RA, Wallace MC. Acute human histopathology of an intracranial aneurysm treated using guglielmi detachable coils: Case report and review of the literature. Neurosurgery 43:1203-1208, 1998.

8. Qureshi AI, Suri MF, Khan J, Kim SH, Fessler RD, Ringer AJ, et al. Endovascular treatment of intracranial aneurysms by using guglielmi detachable coils in awake patients: safety and feasibility. J Neurosurg 94:880-885, 2001.

9. Mawad ME, Cekirge S, Ciceri E, Saatci I. Endovascular treatment of giant and large intracranial aneurysms by using a combination of stent placement and liquid polymer injection. J Neurosurg 96:474-482, 2002.

10. Sedat J, Dib M, Lonjon M, Litrico S, Von Langsdorf D, Fontaine D, Paquis P. Endovascular treatment of ruptured intracranial aneurysms in patients aged 65 years and older: follow-up of 52 patients after 1 year. Stroke 33:2620-2625, 2002.
11. Kremer C, Groden C, Hansen HC, Grzyska U, Zeumer H. Outcome after endovascular treatment of hunt and hess grade IV or V aneurysms: comparison of anterior versus posterior circulation. Stroke 30:2617-2622, 1999.

12. Vallee JN, Aymard A, Vicaut E, Reis M, Merland JJ. Endovascular treatment of basilar tip aneurysms with guglielmi detachable coils: predictors of immediate and long-term results with multivariate analysis 6-year experience. Radiology 226:867-879, 2003.

13. Baltsavias GS, Byrne JV, Halsey J, Coley SC, Sohn MJ, Molyneux AJ. Effects of timing of coil embolization after aneurysmal subarachnoid hemorrhage on procedural morbidity and outcomes. Neurosurgery 47:1320-1329, 2000.

14. Morizane A, Nakahara I, Sakai N, Yanamoto H, Akiyama Y, Sakai H, et al. Endovascular surgery for untreated ruptured aneurysm with symptomatic vasospasm. No Shinkei Geka 27:941946, 1999.

15. Johnston SC, Higashida RT, Barrow DL, Caplan LR, Dion JE, Hademenos G, et al. Recommendations for the endovascular treatment of intracranial aneurysms: a statement for healthcare professionals from the Committee on Cerebrovascular Imaging of the American Heart Association Council on Cardiovascular Radiology. Stroke 33:2536-2544, 2002.

16. Vanninen R, Koivisto T, Saari T, Hernesniemi J, Vapalahti M Ruptured intracranial aneurysms: acute endovascular treatment with electrolytically detachable coils - a prospective randomized study. Radiology 211:325-336, 1999.

17. Molyneux A, Kerr R, Stratton I, Sandercock P, Clarke M, Shrimpton J, Holman R. International Subarachnoid Aneurysm Trial (ISAT) of neurosurgical clipping versus endovascular coiling in 2143 patients with ruptured intracranial aneurysms: a randomised trial. Lancet 360:1267-1274, 2002.

18. Johnston SC, Dudley RA, Gress DR, Ono L. Surgical and endovascular treatment of unruptured cerebral aneurysms at university hospitals. Neurology 52:1799-1805, 1999.

19. Moret J, Cognard C, Weill A, Castaings L, Rey A. [Reconstruction technic in the treatment of wide-neck intracranial aneurysms. Long-term angiographic and clinical results. Apropos of 56 cases]. J Neuroradiol 24:30-44, 1997.

20. Wallace RC, Flom RA, Khayata MH, Dean BL, McKenzie J, Rand JC, et al. The safety and effectiveness of brain arteriovenous malformation embolization using acrylic and particles: the experiences of a single institution. Neurosurgery 37:606-615, 1995 .

21. Ondra SL, Troupp H, George ED, Schwab K. The natural history of symptomatic arteriovenous malformations of the brain: a $24-$ year follow-up assessment. J Neurosurg 73:387-391, 1990.

22. Vinuela F, Dion JE, Duckwiler G, Martin NA, Lylyk P, Fox A, et al. Combined endovascular embolization and surgery in the management of cerebral arteriovenous malformations: experience with 101 cases. J Neurosurg 75:856-864, 1991.

23. Ogilvy CS, Stieg PE, Awad I, Brown RD Jr, Kondziolka D, Rosenwasser R, et al. AHA scientific statement: recommendations for the management of intracranial arteriovenous malformations: a statement for healthcare professionals from a special writing group of the stroke council, American stroke association. Stroke 32:1458-1471, 2001.

24. Sisti MB, Kader A, Stein BM. Microsurgery for 67 intracranial arteriovenous malformations less than $3 \mathrm{~cm}$ in diameter. $\mathrm{J} \mathrm{Neu}$ rosurg 79:653-660, 1993.

25. Purdy PD, Batjer HH, Risser RC, Samson D. Arteriovenous malformations of the brain: choosing embolic materials to enhance safety and ease of excision. J Neurosurg 77:217-222, 1992.

26. Flickinger JC, Pollock BE, Kondziolka D, Lunsford LD. A doseresponse analysis of arteriovenous malformation obliteration after radiosurgery. Int J Radiat Oncol Biol Phys 36:873-879, 1996.

27. Jafar JJ, Davis AJ, Berenstein A, Choi IS, Kupersmith MJ. The effect of embolization with n-butyl cyanoacrylate prior to surgical resection of cerebral arteriovenous malformations. J Neurosurg 78:60-69, 1993.

28. N-butyl cyanoacrylate embolization of cerebral arteriovenous malformations: results of a prospective, randomized, multi-center trial. AJNR Am J Neuroradiol 23:748-755, 2002. 
29. Gobin YP, Laurent A, Merienne L, Schlienger M, Aymard A, Houdart E, et al. Treatment of brain arteriovenous malformations by embolization and radiosurgery. J Neurosurg 85:19-28, 1996.

30. Roy D, Raymond J. The role of transvenous embolization in the treatment of intracranial dural arteriovenous fistulas. Neurosurgery 40:1133-1141, 1997.

31. Murphy KJ, Gailloud P, Venbrux A, Deramond H, Hanley D, Rigamonti D. Endovascular treatment of a grade IV transverse sinus dural arteriovenous fistula by sinus recanalization, angioplasty, and stent placement: technical case report. Neurosurgery 46:497-500, 2000.

32. Vinuela FV, Debrun GM, Fox AJ, Girvin JP, Peerless SJ. Dominant-hemisphere arteriovenous malformations: therapeutic embolization with isobutyl-2-cyanoacrylate. AJNR Am J Neuroradiol 4:959-966, 1983.

33. Nicholson AA. Vascular radiology in trauma. Cardiovasc Intervent Radiol 27:105-120, 2004.

34. McArthur CS, Marin ML. Endovascular therapy for the treatment of arterial trauma. Mt Sinai J Med 71:4-11, 2004.

35. Stockinger ZT, Townsend MC, McSwain NE Jr, Hewitt RL. Acute endovascular management of a subclavian artery injury. $J$ LA State Med Soc 156:262-264, 2004.

36. Assadian A, Senekowitsch C, Rotter R, Zolss C, Strassegger J, Hagmuller GW. Long-term results of covered stent repair of internal carotid artery dissections. J Vasc Surg 40:484-487, 2004.

37. Luo CB, Teng MM, Chang FC, Lirng JF, Chang CY. Endovascular management of the traumatic cerebral aneurysms associated with traumatic carotid cavernous fistulas. AJNR Am J Neuroradiol 25:501-505, 2004.

38. Liu JK, Decker D, Tenner MS, Couldwell WT, Chiles BW 3rd. Traumatic arteriovenous fistula of the posterior inferior cerebellar artery treated with endovascular coil embolization: case report. Surg Neurol 61:255-260, 2004.

39. Lee CY, Yim MB, Kim IM, Son EI, Kim DW. Traumatic aneurysm of the supraclinoid internal carotid artery and an associated carotid-cavernous fistula: Vascular reconstruction performed using intravascular implantation of stents and coils. Case report. J Neurosurg 100:115-119, 2004.

40. Klisch J, Huppertz HJ, Spetzger U, Hetzel A, Seeger W, Schumacher M. Transvenous treatment of carotid cavernous and dural arteriovenous fistulae: results for 31 patients and review of the literature. Neurosurgery 53:836-856, 2003.

41. Shapiro WR, Green SB, Burger PC, Selker RG, VanGilder JC, Robertson JT, et al. A randomized comparison of intra-arterial versus intravenous $\mathrm{BCNU}$, with or without intravenous 5-fluorouracil, for newly diagnosed patients with malignant glioma. $\mathrm{J} \mathrm{Neu-}$ rosurg 76:772-781, 1992.

42. Qureshi AI. Endovascular treatment of cerebrovascular diseases and intracranial neoplasms. Lancet 363:804-813, 2004.

43. Alexander LF, Ward BA. The history of endovascular therapy. Neurosurg Clin N Am 5:383-391, 1994.

44. Hekster RE, Luyendijk W, Tan TI. Spinal-cord compression caused by vertebral haemangioma relieved by percutaneous catheter embolisation. Neuroradiology 3:160-164, 1972.

45. Ahuja A, Gibbons KJ. Endovascular therapy of central nervous system tumors. Neurosurg Clin N Am 5:541-554, 1994.

46. Pandya SK, Nagpal RD. External carotid embolisation-an useful prior adjunct to excision of convexity cerebral meningiomas. Neurol India 24:182-184, 1976.

47. Head, neck, and brain tumor embolization. AJNR Am J Neuroradiol 22:S14-S15, 2001

48. Bendszus M, Martin-Schrader I, Schlake HP, Solymosi L. Embolisation of intracranial meningiomas without subsequent surgery. Neuroradiology 45:451-455, 2003.

49. Brismar J, Cronqvist S. Therapeutic embolization in the external carotid artery region. Acta Radiol Diagn (Stockh) 19:715-731, 1978.

50. Richter HP, Schachenmayr W. Preoperative embolization of intracranial meningiomas. Neurosurgery 13:261-268, 1983.

51. Manelfe C, Guiraud B, David J, Eymeri JC, Tremoulet M, Espagno J, et al. [Embolization by catheterization of intracranial meningiomas]. Rev Neurol (Paris) 128:339-351, 1973.
52. Jungling FD, Wakhloo AK, Hennig J. In vivo proton spectroscopy of meningioma after preoperative embolization. Magn Reson Med 30:155-160, 1993.

53. Khayatya M DB, Flom RA. Efficacy of endovascular treatment of meningiomas: a controlled study. J Neurosurg 78:346A, 1993.

54. Cloughesy TF, Gobin YP, Black KL, Vinuela F, Taft F, Kadkhoda B, et al. Intra-arterial carboplatin chemotherapy for brain tumors: a dose escalation study based on cerebral blood flow. J Neurooncol 35:121-131, 1997.

55. Inamura $\mathrm{T}$, Nomura $\mathrm{T}$, Bartus RT, Black KL. Intracarotid infusion of rmp-7, a bradykinin analog: a method for selective drug delivery to brain tumors. J Neurosurg 81:752-758, 1994.

56. Hacke W, Kaste M, Fieschi C, von Kummer R, Davalos A, Meier $\mathrm{D}$, et al. Randomised double-blind placebo-controlled trial of thrombolytic therapy with intravenous alteplase in acute ischaemic stroke (ECASS II). Second European-Australasian Acute Stroke Study Investigators. Lancet 352:1245-1251, 1998.

57. Tissue plasminogen activator for acute ischemic stroke. The national institute of neurological disorders and stroke RT-PA stroke study group. N Engl J Med 333:1581-1587, 1995.

58. Albers GW, Bates VE, Clark WM, Bell R, Verro P, Hamilton SA. Intravenous tissue-type plasminogen activator for treatment of acute stroke: the Standard Treatment with Alteplase to Reverse Stroke (STARS) Study. JAMA 283:1145-1150, 2000.

59. Qureshi AI. New grading system for angiographic evaluation of arterial occlusions and recanalization response to intra-arterial thrombolysis in acute ischemic stroke. Neurosurgery 50:14051414,2002

60. Qureshi AI, Ringer AJ, Suri MF, Guterman LR, Hopkins LN. Acute interventions for ischemic stroke: present status and future directions. J Endovasc Ther 7:423-428, 2000.

61. Qureshi AI, Pande RU, Kim SH, Hanel RA, Kirmani JF, Yahia AM. Third generation thrombolytics for the treatment of ischemic stroke. Curr Opin Investig Drugs 3:1729-1732, 2002.

62. Qureshi AI, Siddiqui AM, Suri MF, Kim SH, Ali Z, Yahia AM, et al. Aggressive mechanical clot disruption and low-dose intraarterial third-generation thrombolytic agent for ischemic stroke: a prospective study. Neurosurgery 51:1319-1327, 2002.

63. Boulos AS, Levy EI, Bendok BR, Kim SH, Qureshi AI, Guterman LR, et al. Evolution of neuroendovascular intervention: a review of advancement in device technology. Neurosurgery 54: 438-452, 2004.

64. del Zoppo GJ, Higashida RT, Furlan AJ, Pessin MS, Rowley HA, Gent M. PROACT: a phase II randomized trial of recombinant pro-urokinase by direct arterial delivery in acute middle cerebral artery stroke. PROACT investigators. Prolyse in acute cerebral thromboembolism. Stroke 29:4-11, 1998.

65. Furlan A, Higashida R, Wechsler L, Gent M, Rowley H, Kase C, et al. Intra-arterial prourokinase for acute ischemic stroke. The PROACT II study: a randomized controlled trial. Prolyse in acute cerebral thromboembolism. JAMA 282:2003-2011, 1999.

66. Lewandowski CA, Frankel M, Tomsick TA, Broderick J, Frey J, Clark W, et al. Combined intravenous and intra-arterial r-tPA versus intra-arterial therapy of acute ischemic stroke: Emergency Management of Stroke (EMS) Bridging Trial. Stroke 30:25982605,1999

67. Mahon BR, Nesbit GM, Barnwell SL, Clark W, Marotta TR, Weill A, Teal PA, Qureshi AI. North American clinical experience with the EKOS MicroLysUS infusion catheter for the treatment of embolic stroke. AJNR Am J Neuroradiol 24:534-538, 2003.

68. Bellon RJ, Putman CM, Budzik RF, Pergolizzi RS, Reinking GF, Norbash AM. Rheolytic thrombectomy of the occluded internal carotid artery in the setting of acute ischemic stroke. AJNR Am J Neuroradiol 22:526-530, 2001.

69. Gobin YP, Starkman S, Duckwiler GR, Grobelny T, Kidwell CS, Jahan R, et al. Merci 1: a phase 1 study of mechanical embolus removal in cerebral ischemia. Stroke 35:2848-2854, 2004.

70. Goose Neck snares. Available at: http://www.Microvena.Com/. Accessed December 29, 2004.

71. Kerber CW, Barr JD, Berger RM, Chopko BW. Snare retrieval of intracranial thrombus in patients with acute stroke. J Vasc Interv Radiol 13:1269-1274, 2002. 
72. Edna Robertson HN, David M. History Dentistry Research Group. A composition on 'stents' available [online] at http:// www.rcpsglasg.ac.uk/hdrg/2003oct8.htm. Accessed December 29, 2004.

73. Yahia AM QA, Boulos AS, Kirmani JF, Kim SH, Siddiqui AM, Hopkins LN. Balloon expandable stents for intracranial arterial occlusion in patients with ischemic stroke. Paper presented at the 7th International Symposium on Thrombolysis and Acute Stroke Therapy, Lyon, France, May 27-29, 2002.

74. Kim SH, Qureshi AI, Levy EI, Hanel RA, Siddiqui AM, Hopkins LN. Emergency stent placement for symptomatic acute carotid artery occlusion after endarterectomy. Case report. J Neurosurg 101:151-153, 2004

75. Gershlick AH. Role of stenting in coronary revascularisation. Heart 86:104-112, 2001.

76. King SB 3rd, Schlumpf M. Ten-year completed follow-up of percutaneous transluminal coronary angioplasty: the early Zurich experience. J Am Coll Cardiol 22:353-360, 1993.

77. Halloran PF. Sirolimus and cyclosporin for renal transplantation. Lancet 356:179-180, 2000

78. Zohlnhofer D, Klein CA, Richter T, Brandl R, Murr A, Nuhrenberg $\mathrm{T}$, et al. Gene expression profiling of human stent-induced neointima by cDNA array analysis of microscopic specimens retrieved by helix cutter atherectomy: detection of FK506-binding protein 12 upregulation. Circulation 103:1396-1402, 2001.

79. Cohen DJ, Ramee S, Baim DS, Sharma S, Carrozza JP, Cosgrove $\mathrm{R}$, et al. Economic assessment of rheolytic thrombectomy versus intracoronary urokinase for treatment of extensive intracoronary thrombus: results from a randomized clinical trial. Am Heart $J$ 142:648-656, 2001.

80. Silva JA, Ramee SR, Cohen DJ, Carrozza JP, Popma JJ, Lansky AA, et al. Rheolytic thrombectomy during percutaneous revascularization for acute myocardial infarction: experience with the Angiojet catheter. Am Heart J 41:353-359, 2001.

81. Broderick JP, Hacke W. Treatment of acute ischemic stroke. Part I: recanalization strategies. Circulation 106:1563-1569, 2002.

82. Berlis A, Lutsep H, Barnwell S, Norbash A, Wechsler L, Jungreis $\mathrm{CA}$, et al. Mechanical thrombolysis in acute ischemic stroke with endovascular photoacoustic recanalization. Stroke 35:1112-1116, 2004.

83. North American Symptomatic Carotid Endarterectomy Trial collaborators. Beneficial effect of carotid endarterectomy in symptomatic patients with high-grade carotid stenosis. $N$ Engl J Med 325:445-453, 1991.

84. Barnett HJ, Taylor DW, Eliasziw M, Fox AJ, Ferguson GG, Haynes RB, et al. Benefit of carotid endarterectomy in patients with symptomatic moderate or severe stenosis. North American symptomatic carotid endarterectomy trial collaborators. $N$ Engl J Med 339:1415-1425, 1998.

85. Randomised trial of endarterectomy for recently symptomatic carotid stenosis: final results of the MRC European Carotid Surgery Trial (ECST). Lancet 351:1379-1387, 1998.

86. Endarterectomy for asymptomatic carotid artery stenosis. Executive committee for the asymptomatic carotid atherosclerosis study. JAMA 273:1421-1428, 1995.

87. Stukenborg GJ. Comparison of carotid endarterectomy outcomes from randomized controlled trials and Medicare administrative databases. Arch Neurol 54:826-832, 1997.

88. Wennberg DE, Lucas FL, Birkmeyer JD, Bredenberg CE, Fisher ES. Variation in carotid endarterectomy mortality in the medicare population: trial hospitals, volume, and patient characteristics. JAMA 279:1278-1281, 1998.

89. Goldstein LB, McCrory DC, Landsman PB, Samsa GP, Ancukiewicz M, Oddone EZ, Matchar DB. Multicenter review of preoperative risk factors for carotid endarterectomy in patients with ipsilateral symptoms. Stroke 25:1116-1121, 1994.

90. Goldstein LB, Samsa GP, Matchar DB, Oddone EZ. Multicenter review of preoperative risk factors for endarterectomy for asymptomatic carotid artery stenosis. Stroke 29:750-753, 1998.

91. Rothwell PM, Slattery J, Warlow CP. Clinical and angiographic predictors of stroke and death from carotid endarterectomy: systematic review. BMJ 315:1571-1577, 1997.

92. Dotter CT, Judkins MP. Transluminal treatment of arterioscle- rotic obstruction. Description of a new technic and a preliminary report of its application. Circulation 30:654-670, 1964.

93. Gruntzig A, Kumpe DA. Technique of percutaneous transluminal angioplasty with the gruntzig ballon catheter. AJR Am J Roentgenol 132:547-552, 1979.

94. Mullan S, Duda EE, Patronas NJ. Some examples of balloon technology in neurosurgery. J Neurosurg 52:321-329, 1980.

95. Hanel RA, Xavier AR, Kirmani JF, Yahia AM, Qureshi AI Management of carotid artery stenosis: comparing endarterectomy and stenting. Curr Cardiol Rep 5:153-159, 2003.

96. Yadav I. Stenting and angioplasty with protection in patients at high risk for endarterectomy. Paper presented at the 15th Annual Transcatheter Cardiovascular Therapeutics Symposium, Washington, DC, pp 153-159, September 15-17, 2003.

97. Archer T. Acculink for revascularization of carotid in high-risk patients. Paper presented at the American College of Cardiology 52nd Second Annual Meeting Scientific Session, Chicago, IL, March 29-April 2, 2003.

98. Endovascular versus surgical treatment in patients with carotid stenosis in the carotid and vertebral artery transluminal angioplasty study (CAVATAS): a randomised trial. Lancet 357:17291737, 2001.

99. Hobson R. Carotid Revascularization Endarterectomy Versus Stent Trial (CREST). Stroke 34:238, 2003.

100. Qureshi AI, Luft AR, Sharma M, Guterman LR, Hopkins LN. Prevention and treatment of thromboembolic and ischemic complications associated with endovascular procedures. Part II-clinical aspects and recommendations. Neurosurgery 46:1360-1375, 2000.

101. Mukherjee D, Kalahasti V, Roffi M, Bhatt DL, Kapadia SR, Bajzer C, et al. Self-expanding stents for carotid interventions: comparison of nitinol versus stainless-steel stents. J Invasive Cardiol 13:732-735, 2001.

102. Qureshi AI, Ziai WC, Yahia AM, Mohammad Y, Sen S, Agarwal $\mathrm{P}$, et al. Stroke-free survival and its determinants in patients with symptomatic vertebrobasilar stenosis: a multicenter study. $\mathrm{Neu}$ rosurgery 52:1033-1039, 2003.

103. Hofmann R, Kerschner K, Steinwender C, Kypta A, Bibl D, Leisch F. Abciximab bolus injection does not reduce cerebral ischemic complications of elective carotid artery stenting: a randomized study. Stroke 33:725-727, 2002.

104. Markus HS, Clifton A, Buckenham T, Brown MM. Carotid angioplasty. Detection of embolic signals during and after the procedure. Stroke 25:2403-2406, 1994.

105. McCleary AJ, Nelson M, Dearden NM, Calvey TA, Gough MJ. Cerebral haemodynamics and embolization during carotid angioplasty in high-risk patients. Br J Surg 85:771-774, 1998.

106. Grube E, Colombo A, Hauptmann E, Londero H, Reifart N, Gerckens U, et al. Initial multicenter experience with a novel distal protection filter during carotid artery stent implantation. Catheter Cardiovasc Interv 58:139-146, 2003.

107. van Heesewijk HP, Vos JA, Louwerse ES, Van Den Berg JC, Overtoom TT, Ernst SM, Mauser HW, et al. New brain lesions at MR imaging after carotid angioplasty and stent placement. $R a-$ diology 224:361-365, 2002.

108. Barth A, Remonda L, Lovblad KO, Schroth G, Seiler RW. Silent cerebral ischemia detected by diffusion-weighted MRI after carotid endarterectomy. Stroke 31:1824-1828, 2000.

109. Theron J. The techniques for distal protection during CAS. Radiology 201:627-636, 1966

110. Adami CA, Scuro A, Spinamano L, Galvagni E, Antoniucci D, Farello GA, et al. Use of the parodi anti-embolism system in carotid stenting: Italian trial results. J Endovasc Ther 9:147-154, 2002.

111. Whitlow PL, Lylyk P, Londero H, Mendiz OA, Mathias K, Jaeger H, Parodi J, Schonholz C, Milei J. Carotid artery stenting protected with an emboli containment system. Stroke 33:1308-1314, 2002.

112. Reimers B, Corvaja N, Moshiri S, Sacca S, Albiero R, Di Mario C, Pascotto P, Colombo A. Cerebral protection with filter devices during carotid artery stenting. Circulation 104:12-15, 2001.

113. Mubarak N. Multicenter evalution of carotid artery stenting with a filter protection system. J Am Coll Cardiol 39, 2002. 
114. Wityk RJ, Lehman D, Klag M, Coresh J, Ahn H, Litt B. Race and sex differences in the distribution of cerebral atherosclerosis. Stroke 27:1974-1980, 1996.

115. Bogousslavsky J, Barnett HJ, Fox AJ, Hachinski VC, Taylor W. Atherosclerotic disease of the middle cerebral artery. Stroke 17: 1112-1120, 1986.

116. Chimowitz MI, Kokkinos J, Strong J, Brown MB, Levine SR, Silliman S, et al. The warfarin-aspirin symptomatic intracranial disease study. Neurology 45:1488-1493, 1995.

117. Thijs VN, Albers GW. Symptomatic intracranial atherosclerosis: Outcome of patients who fail antithrombotic therapy. Neurology 55:490-497, 2000.

118. Kirmani JF, Hassan A, Ahmed S, Chowdhury F, Rahman A, Pullicino P. A comparative prospective evaluation of stenoocclusive disease in patients with ischemic stroke using magnetic resonance angiography and digital subtraction angiography. Paper presented at the 27th Annual Meeting of the American Society of Neuroimaging, Phoenix, AZ, January 28-31, 2004.

119. Qureshi AI, Suri MF, Ali Z, Kim SH, Fessler RD, Ringer AJ, et al. Role of conventional angiography in evaluation of patients with carotid artery stenosis demonstrated by Doppler ultrasound in general practice. Stroke 32:2287-2291, 2001.

120. Stenting of symptomatic atherosclerotic lesions in the vertebral or intracranial arteries (SSYLVIA): study results. Stroke 35:13881392,2004

121. Ali Z. Single center stidy to evaluate long-term effectiveness of angioplasty and/or stent placement for intracranial atherosclerotic disease. Neurology 58:A313, 2002.

122. Marks MP, Marcellus M, Norbash AM, Steinberg GK, Tong D, Albers GW. Outcome of angioplasty for atherosclerotic intracranial stenosis. Stroke 30:1065-1069, 1999.

123. Gomez CR, Misra VK, Liu MW, Wadlington VR, Terry JB, Tulyapronchote R, et al. Elective stenting of symptomatic basilar artery stenosis. Stroke 31:95-99, 2000.

124. Sousa JE, Serruys PW, Costa MA. New frontiers in cardiology: Drug-eluting stents: part I. Circulation 107:2274-2279, 2003.

125. Sousa JE, Serruys PW, Costa MA. New frontiers in cardiology: Drug-eluting stents: part II. Circulation 107:2383-2389, 2003.

126. Sousa JE, Costa MA, Abizaid A, Sousa AG, Feres F, Mattos LA, et al. Sirolimus-eluting stent for the treatment of in-stent restenosis: a quantitative coronary angiography and three-dimensional intravascular ultrasound study. Circulation 107:24-27, 2003.

127. Lemos PA, Lee CH, Degertekin M, Saia F, Tanabe K, Arampatzis CA, et al. Early outcome after sirolimus-eluting stent implantation in patients with acute coronary syndromes: insights from the rapamycin-eluting stent evaluated at Rotterdam Cardiology Hospital (research) registry. J Am Coll Cardiol 41:2093-2099, 2003.

128. Bousser MG. Cerebral venous thrombosis: diagnosis and management. J Neurol 247:252-258, 2000.

129. Bakshi R, Lindsay BD, Bates VE, et al. Cerebral venous infarctions presenting as enhancing space-occupying lesions: MRI findings. J Neuroimaging 8:210-215, 1998.

130. Wasay M, Bakshi R, Kojan S, et al. Nonrandomized comparison of local urokinase thrombolysis versus systemic heparin anticoagulation for superior sagittal sinus thrombosis. Stroke 32:23102317, 2001.

131. de Bruijn SF, Stam J. Randomized, placebo-controlled trial of anticoagulant treatment with low-molecular-weight heparin for cerebral sinus thrombosis. Stroke 30:484-488, 1999.

132. Preter M, Tzourio C, Ameri A, Bousser MG. Long-term prognosis in cerebral venous thrombosis. Follow-up of 77 patients. Stroke 27:243-246, 1996.

133. Smith AG, Cornblath WT, Deveikis JP. Local thrombolytic therapy in deep cerebral venous thrombosis. Neurology 48:16131619, 1997.

134. Fink JN, McAuley DL. Safety of anticoagulation for cerebral venous thrombosis associated with intracerebral hematoma. $\mathrm{Neu}$ rology 57:1138-1139, 2001.

135. Wasay M, Bakshi R, Suleman K, Bobustuc G, Dubey N. Superior sagittal sinus thrombosis due to lithium: local urokinase thrombolysis treatment. Neurology 54:532-533, 2000.

136. Frey JL, Muro GJ, McDougall CG, Dean BL, Jahnke HK. Cere- bral venous thrombosis: combined intrathrombus rtPA and intravenous heparin. Stroke 30:489-494, 1999.

137. Horowitz M, Purdy P, Unwin H, Carstens G 3rd, Greenlee R, Hise J, et al. Treatment of dural sinus thrombosis using selective catheterization and urokinase. Ann Neurol 38:58-67, 1995.

138. Chaloupka JC, Mangla S, Huddle DC. Use of mechanical thrombolysis via microballoon percutaneous transluminal angioplasty for the treatment of acute dural sinus thrombosis: case presentation and technical report. Neurosurgery 45:650-656, 1999.

139. Malek AM, Higashida RT, Balousek PA, Phatouros CC, Smith WS, Dowd CF, et al. Endovascular recanalization with balloon angioplasty and stenting of an occluded occipital sinus for treatment of intracranial venous hypertension: technical case report. Neurosurgery 44:896-901, 1999.

140. Baker MD, Opatowsky MJ, Wilson JA, Glazier SS, Morris PP. Rheolytic catheter and thrombolysis of dural venous sinus thrombosis: a case series. Neurosurgery 48:487-493, 2001.

141. Choi IS, Tantivatana J. Neuroendovascular management of intracranial and spinal tumors. Neurosurg Clin N Am 11:167-185, 2000.

142. Standard LH. Principals of neuroendovascular intervention. Chicago, IL: American Association of Neurological Surgeons, 1995.

143. Allen GS, Ahn HS, Preziosi TJ, Battye R, Boone SC, Chou SN, et al. Cerebral arterial spasm-a controlled trial of nimodipine in patients with subarachnoid hemorrhage. N Engl J Med 308:619624, 1983.

144. Haley EC Jr, Kassell NF, Torner JC. The international cooperative study on the timing of aneurysm surgery. The North American experience. Stroke 23:205-214, 1992.

145. Longstreth WT Jr, Nelson LM, Koepsell TD, van Belle G. Clinical course of spontaneous subarachnoid hemorrhage: a population-based study in King County, Washington. Neurology 43: 712-718, 1993.

146. Yamamoto Y, Smith RR, Bernanke DH. Mechanism of action of balloon angioplasty in cerebral vasospasm. Neurosurgery 30:1-5, 1992.

147. Higashida RT, Halbach VV, Cahan LD, Brant-Zawadzki M, Barnwell S, Dowd C, et al. Transluminal angioplasty for treatment of intracranial arterial vasospasm. J Neurosurg 71:648653, 1989.

148. Milburn JM, Moran CJ, Cross DT 3rd, Diringer MN, Pilgram TK, Dacey RG Jr. Increase in diameters of vasospastic intracranial arteries by intraarterial papaverine administration. J Neurosurg 88:38-42, 1998.

149. Hanel RA, Xavier AR, Mohammad Y, Kirmani JF, Yahia AM, Qureshi AI. Outcome following intracerebral hemorrhage and subarachnoid hemorrhage. Neurol Res 24(Suppl 1):S58-S62, 2002.

150. Carhuapoma JR, Qureshi AI, Tamargo RJ, Mathis JM, Hanley DF. Intra-arterial papaverine-induced seizures: case report and review of the literature. Surg Neurol 56:159-163, 2001.

151. Qureshi AI, Frankel MR. Recognition and management of subarachnoid hemorrhage. Heart Dis Stroke 3:270-274, 1994.

152. Qureshi AI, Sung GY, Razumovsky AY, Lane K, Straw RN, Ulatowski JA. Early identification of patients at risk for symptomatic vasospasm after aneurysmal subarachnoid hemorrhage. Crit Care Med 28:984-990, 2000.

153. J Wada RT. Intracarotid injection of sodium amobarbital for the lateralization of cerebral speech dominance. J Neurosurg 17:226, 1960.

154. Trenerry MR. Neuropsychologic assessment in surgical treatment of epilepsy. Mayo Clin Proc 71:1196-1200, 1996.

155. Trenerry MR, Loring DW. Intracarotid amobarbital procedure. The Wada test. Neuroimaging Clin N Am 5:721-728, 1995.

156. Barr JD, Mathis JM, Horton JA. Provocative pharmacologic testing during arterial embolization. Neurosurg Clin N Am 5:403411, 1994.

157. Brassel F, Weissenborn K, Ruckert N, Hussein S, Becker H. Superselective intra-arterial amytal (Wada test) in temporal lobe epilepsy: basics for neuroradiological investigations. Neuroradiology 38:417-421, 1996. 
158. Jack CR Jr, Nichols DA, Sharbrough FW, Marsh WR, Petersen RC. Selective posterior cerebral artery amytal test for evaluating memory function before surgery for temporal lobe seizure. $R a$ diology 168:787-793, 1988.

159. Jack CR Jr, Nichols DA, Sharbrough FW, Marsh WR, Petersen $\mathrm{RC}$, et al. Selective posterior cerebral artery injection of amytal: new method of preoperative memory testing. Mayo Clin Proc 64:965-975, 1989.
160. Urbach H, Klemm E, Linke DB, Behrends K, Biersack HJ, Schramm J, et al. Posterior cerebral artery Wada test: sodium amytal distribution and functional deficits. Neuroradiology 43: 290-294, 2001.

161. Fitzsimmons BF, Marshall RS, Pile-Spellman J, Lazar RM. Neurobehavioral differences in superselective Wada testing with amobarbital versus lidocaine. AJNR Am J Neuroradiol 24:14561460, 2003. 